Running Head: THE MANHATTAN EFFECT

Author accepted version: Please see the published version for the final article:

Hui, C. M., Finkel, E. J., Fitzsimons, G. M., Kumashiro, M., \& Hofmann, W. (2014). The Manhattan effect: When relationship commitment fails to promote support for partners' interests. Journal of Personality and Social Psychology, 106, 546-570. ISSN 0022-3514.

\title{
The Manhattan Effect:
}

\section{When Relationship Commitment Fails to Promote Support for Partners' Interests}

\author{
Chin Ming Hui
}

University of Chicago

Eli J. Finkel

Northwestern University

Gráinne M. Fitzsimons

Duke University

Madoka Kumashiro

Goldsmiths, University of London

\author{
Wilhelm Hofmann \\ University of Cologne
}

Date: November 20, 2013 


\begin{abstract}
Research on close relationships has frequently contrasted one's own interests with the interests of the partner or the relationship, and has tended to view the partner's and the relationship's interests as inherently aligned. The present article demonstrated that relationship commitment typically causes people to support their partner's personal interests, but that this effect gets weaker to the extent that those interests misalign or even threaten the relationship. Studies 1a and 1b showed that (a) despite their strong correlation, partner-oriented and relationship-oriented concerns in goal-directed behaviors are separable; and (b) relationship commitment strengthens only the link between relationship-oriented motivation and the goal pursuit (not the link between partner-oriented motivation and the goal pursuit). The remaining seven studies zero in on circumstances in which the partner's and the relationship's interests are in conflict, demonstrating that (c) relationship commitment reliably increases the tendency to support the partner's personal interests when those interests do not pose a strong threat to the relationship, but that (d) this effect becomes weaker—and even reverses direction—as the relationship threat posed by the partner's interests becomes stronger. The reduction or reversal of the positive link between relationship commitment and pro-partner behaviors in such situations is termed the Manhattan effect. These findings suggest that the partner-versus-relationship conflicts provide fertile ground for novel theorizing and empirical investigations and that relationship commitment appears to be less of a partner-promoting construct than relationship science has suggested; instead, its role appears to be focused on promoting the interests of the relationship.
\end{abstract}

\title{
Abstract Word Count: 249
}

KEYWORDS: Romantic relationships, commitment, social support, interdependence theory 


\section{The Manhattan Effect:}

\section{When Relationship Commitment Fails to Promote Support for Partners' Interests}

"I don't think you oughta go to London"

-Isaac to Tracy in Manhattan

In Manhattan (1979), the famed film director Woody Allen casts himself as Isaac, a 42 yearold writer dating an earnest and adoring high school senior named Tracy. Isaac takes their relationship lightly due to their 25-year age gap; he is consistently frank with her that the two of them lack a future. Indeed, when she tells him that she was admitted to a prestigious school in London, and explains that she is reluctant to go because she dreads the thought of being away from him, he effuses about the marvelous opportunity and dismisses her relationship worries. After breaking up with Tracy for another woman, however, Isaac has a change of heart, and decides to commit to a real relationship with Tracy. He runs to her apartment to rekindle the relationship, only to learn that she is heading to the airport for her trip to London. Now that he wants a serious relationship with her, the prospect of her departure distresses him, and he begs her not to go. He expresses concern that the two of them will never be able to rebuild their relationship because she will become a different person.

That is, as a result of Isaac's change in commitment to Tracy, he no longer sees her semester abroad as a marvelous opportunity for growth. Instead, he focuses on the potential threat to the relationship. We suggest that the Manhattan example illustrates an important relationship phenomenon, one in which the robust positive association of relationship commitment with willingness to support the partner's interests (Rusbult, Olsen, Davis, \& Hannon, 2001) becomes weaker as relationship threat increases-even becoming negative in situations of extreme relationship threat.

Extant interdependence theory analyses in close relationships have reported no cases in which psychological commitment to one's relationship predicts behavior that undermines the partner's personal interests (for a recent review, see Rusbult, Agnew, \& Arriaga, 2012). Indeed, a vast body of 
work has shown a uniformly positive link between relationship commitment and pro-partner behaviors. We suggest that a major reason why scholars have only found evidence of this positive link is that relationship commitment has been studied exclusively in strain test situations in which pro-partner behaviors work against self-interests but in alignment with the relationship's interests-that is, in situations in which the partner's and the relationship's interests have been confounded. It is not surprising that, in such situations, highly committed individuals consistently engage in pro-partner behaviors, as those behaviors simultaneously benefit the relationship. However, in many interpersonal situations, like Isaac's, the well-being of the partner and the relationship do not align and therefore individuals may have to choose one at the expense of the other. Despite the centrality of relationship commitment to interdependence analyses of close relationships (Rusbult \& Buunk, 1993; Rusbult et al., 2001), it remains unclear about how highly committed individuals navigate circumstances in which the partner's and the relationship's interests are in conflict.

\section{Transformation of Motivation and Pro-partner Behaviors in Close Relationships}

People depend on their partners to enhance their own well-being (e.g., Kelley \& Thibaut, 1978; Murray \& Holmes, 2011). They rely on their relationship partners to share the ups and downs of daily life (Custrona, 1996; Gable \& Reis, 2010), fulfill basic needs (La Guardia \& Patrick, 2008), and support their goal pursuit (Fitzsimons \& Finkel, 2010; Rusbult, Finkel, \& Kumashiro, 2009). Indeed, mutual support for each other's personal interests is an indispensable part of close relationships and personal growth (Reis, Collins, \& Berscheid, 2000). However, supporting the partner's interests may often be costly, requiring that individuals' sacrifice their own interests (Murray \& Holmes, 2011). Despite these costs, individuals are frequently willing to enhance the partner's personal interests (Clark \& Grote, 1998; Clark \& Reis, 1988). What motivates individuals to do so?

According to interdependence theory (Kelley \& Thibaut, 1978), individuals arrive at dyadic situations with self-oriented, gut-level impulses known as given preferences. To the extent that 
individuals' pro-relationship behaviors often involve personal costs or threats, such as mental fatigue and risk of exploitation (Garcia \& Harrison, 2007; Latane \& Darley, 1970; Murray, Holmes, \& Collins, 2006), self-oriented impulses frequently conflict with other-oriented prosocial behaviors. In line with this reasoning, when individuals have limited mental resources to inhibit these impulses, they tend to prioritize self-interests at the expense of the other person's interests (Burnette et al., in press; Finkel \& Campbell, 2001; Finkel, DeWall, Slotter, Oaten, \& Foshee, 2009) and to exhibit impoverished tendencies toward perspective taking and prosocial behaviors (DeWall, Baumeister, Gailliot, \& Maner, 2008; Fennis, 2011; Lin, Keysar, \& Epley, 2010).

However, given preferences do not necessarily guide behaviors. Individuals may take into account broader considerations, including moral principles, long-term goals, and concerns for a partner's well-being. This process of altering one's given preferences after accounting for broader considerations is termed transformation of motivation, and the resultant preferences are termed effective preferences (Kelley \& Thibaut, 1978), which directly guide behaviors. Pro-partner behaviors in close relationships are frequently facilitated by the transformation process (Finkel, Rusbult, Kumashiro, \& Hannon, 2002; Impett \& Gordon, 2008; Rusbult, Verette, Whitney, Slovik, \& Lipkus, 1991). Transformation of motivation can be driven by different kinds of interpersonal concerns and therefore can yield different profiles of effective preferences (e.g., Kelley et al., 2003; Van Lange, 2000). For example, pro-partner behaviors can be motivated by concerns for the other's well-being, such as an altruistic orientation that inspires preferences for maximizing the outcome of the other ("MaxOther") and a cooperative orientation that inspires preferences for maximizing the joint outcomes ("MaxJoint"; e.g., Liebrand \& McClintock, 1988; Lurie, 1987). Pro-partner behaviors can also be motivated by future-oriented interpersonal concerns for the relationship (e.g., Nesse, 2001; Van Lange \& Joireman, 2008). In short, pro-partner behaviors can be motivated not only by concerns for the partner's well-being, but also by concerns for the relationship's. Therefore, consistent with the 
established theorizing, it is plausible that relationship commitment motivates support for the partner via partner-oriented concerns, relationship-oriented concerns, or both.

\section{A Revised Interdependence Analysis of Relationship Commitment}

Relationship commitment is a subjective state of dependence on another person (Rusbult \& Buunk, 1993). At its core, it indexes the intentions to prevent the termination of mutual interdependence (M. P. Johnson, 1991; Kelley et al., 2003). Although relationship commitment can also be derived from one's structural constraints and moral values (e.g., Adams \& Jones, 1997; Blais, Sabourin, Boucher, \& Vallerand, 1990; M. P. Johnson, 1999), interdependence theory analyses have been dominated by the component of relationship commitment that comes from one's personal attraction to the relationship or the intrinsic value of the relationship (Le \& Agnew, 2003; Rusbult, 1991). The present research, too, investigates this personal (rather than structural and moral) component of relationship commitment.

Specifically, relationship commitment encompasses psychological attachment to the partner, a long-term orientation toward the relationship, and an intention to persist in the relationship (e.g., Arriaga \& Agnew, 2001). Relationship commitment, which emerges when people are satisfied with the relationship, have poor alternatives to the relationship, and have invested a lot into the relationship (Le \& Agnew, 2003; Rusbult, 1980), is a major predictor of relationship maintenance behaviors and relationship stability (Le \& Agnew, 2003; Le, Dove, Agnew, Korn, \& Mutso, 2010). It also motivates many behaviors that promote the partner's and the relationship's interests even at costs to the self (Rusbult et al., 2001). For example, relationship commitment predicts the willingness to sacrifice one's self-interests for the partner and the relationship (Powell \& Van Vugt, 2003; Van Lange, Agnew, Harinck, \& Steemers, 1997; Van Lange, Rusbult, et al., 1997), to forgive the partner's transgressions (Cann \& Baucom, 2004; Finkel et al., 2002; Karremans, Van Lange, \& Holland, 2005; McCullough et al., 1998), and to accommodate in response to the partner's inconsiderate behavior (Menzies-Toman \& 
Lydon, 2005; Rusbult et al., 1991; Tran \& Simpson, 2009; Wieselquist, Rusbult, Foster, \& Agnew, 1999). Relationship commitment also inhibits behaviors that compromise the partner's and the relationship's interests, such as aggression (Rhoades, Stanley, Kelmer, \& Markman, 2010; Slotter et al., 2012) and infidelity (Drigotas, Safstrom, \& Gentilia, 1999; Le, Korn, Crockett, \& Loving, 2011). Rusbult and her colleagues (e.g., Finkel et al., 2002; Rusbult \& Buunk, 1993; Rusbult et al., 2001) have offered three overlapping and yet distinguishable interdependence-theory-based arguments to account for the importance of relationship commitment in pro-partner behaviors: a self-oriented argument, a relationship-oriented argument, and a partner-oriented argument. The self-oriented argument is that relationship commitment broadens one's temporal perspective regarding self-interest. Highly committed individuals are motivated to develop and maintain patterns of reciprocal cooperation, in which one person's long-term well-being is likely to be enhanced if he or she helps the partner today at costs to the self, as the partner is likely to be in a position to reciprocate that helping in the future (Axelrod, 1984; Van Lange \& Joireman, 2008; Wu \& Axelrod, 1995). The relationshiporiented argument is that relationship commitment heightens concerns for relationship well-being. Given that highly committed individuals are more dependent on the relationship, they should be more willing to relinquish self-interests to prevent relationship dissolution (Rusbult, 1980). The partneroriented argument is that relationship commitment inspires "collectivistic orientation, including inclinations to respond to [the partner]'s needs in a relatively unconditional manner- [the supporter] may endure cost and exert effort without calculating what he will receive in return" (Rusbult, Olsen, Davis, \& Hannon, 2004, p.293), resulting in prosocial responses that are "rather thoroughly otheroriented" (Finkel \& Rusbult et al., 2002, p. 959). (To be sure, these partner-oriented concerns could be intrinsically rewarding to the extent that the supporter truly cares the partner's well-being; cf. Rempel, Holmes, \& Zanna, 1985) 
There is no debate that relationship commitment, a construct that is fundamentally oriented toward the maintenance of the relationship (M. P. Johnson, 1991; Rusbult et al., 2001), promotes relationship-oriented motivations. For example, highly committed individuals devalue attractive romantic alternatives (D. J. Johnson \& Rusbult, 1989; Lydon, Fitzsimons, \& Naidoo, 2003), and affirm the superiority of the relationship in the presence either of disapproving social networks (Lehmiller \& Agnew, 2006).

However, we suggest that partner-oriented motivations for commitment-inspired behaviors might be much less important than scholars have assumed - that the primary reason why such partneroriented motivations have seemed important in the existing literature is that they have been confounded with relationship-oriented motivations. That is, to protect relationship stability, individuals may want to be instrumental and responsive to the partner's personal needs, even at significant cost to the self, as doing so is likely to foster their partner's trust and commitment (Clark \& Grote, 1998; Murray \& Holmes, 2009; Wieselquist et al., 1999). In other words, partner-oriented concerns typically benefit relationship-oriented concerns indirectly and, accordingly, align with relationship-oriented concerns (cf. Murray et al., 2009). It is plausible that relationship commitment might no longer predict pro-partner behaviors when partner-oriented motivations happen to be detrimental to relationshiporiented motivations. Accordingly, it is important to expand the interdependence analysis to encompass the effects of relationship commitment in the heretofore-neglected category of interpersonal situations in which the partner's interests conflict with the relationship's interests. By pitting the two types of interests against each other, we can understand the relative contribution of each to commitment-inspired behaviors.

\section{Conflicts between the Partner's Interests and the Relationship's Interests}

As noted previously, partner-oriented and relationship-oriented motivations frequently align in everyday life and may independently or jointly facilitate pro-partner behaviors. For instance, 
individuals may forgive a partner's transgression because they want to make their partner less guilty (a partner-oriented concern) or to repair the relationship (a relationship-oriented concern). Individuals may decline a promotion at work that comes along with an increased expectation of time commitment because they want to make their partner happy (a partner-oriented concern) or to make the relationship flourish (a relationship-oriented concern). However, just because partner-oriented and relationshiporiented motivations frequently align in everyday life, and just because these are the sorts of situations that relationships scholars have investigated, does not mean that these are the only sorts of situations that influence relationships.

In this article, we investigate situations in which the partner's interests may be incompatible with the relationship's interests, a construct that relationships researchers frequently discuss but insufficiently elaborate. We suggest that the relationship exists as a separate entity beyond each individual's experience of it. Relationship interests encompass relationship longevity and the maintenance of a functioning interdependence that supports mutual needs. Achieving such ends is more than just maintaining the self's and the partner's relationship commitment. Indeed, bolstering relationship commitment is insufficient for sustaining the relationship's interest if the threat derives not from either partner's low investment in the relationship but rather from other threats to the core essence of the relationship, such as a partner's infertility in a couple that has built the relationship around creating a family together or the military deployment that undercuts the relationship's ability to meet the partners' needs.

In the partner-versus-relationship conflict, we assume that the partner's personal interests pose threat to the relationship's interests by making the relationship unstable or compromising its ability to support the relationship-dependent needs of both partners. Even though pro-partner behavior generally bolsters the partner's trust and commitment (Wieselquist et al., 1999), in such conflict, this relationship benefit could be offset by the bigger relationship costs the behavior incurs. 
The partner-versus-relationship conflict can manifest itself in several different forms. It may involve a specific interest of the partner that may itself be incompatible with the relationship's interests (e.g., the partner's goal to seek tenure at a prestigious institution). It may involve a situation in which resource constraints make it difficult or impossible to maximize the well-being of the partner and the relationship simultaneously (e.g., inadequate savings to finance both a graduate degree and a wedding). It may involve a situation in which the partner's pursuit of a specific interest transpires in a context that happens to involve potential relationship threats (e.g., a dancing hobby which involves interacting with many members of opposite sex).

To our knowledge, scholars have not systematically examined how individuals navigate partner-versus-relationship conflicts. However, such conflicts are both common and consequential; they are diagnostic of whether individuals engage in transformation of motivation predominantly for partner- or relationship-oriented motivations. In an extreme conflict, a predominant partner-oriented motivation may yield altruistic behaviors directed toward maximizing the partner's well-being even if such behaviors might ultimately end the relationship, whereas a predominant relationship-oriented motivation may yield relationship stability at the expense of the partner's well-being.

Systematic analysis of partner-versus-relationship conflict allows for investigations of situations where such conflict may reduce the positive association between relationship commitment and pro-partner behaviors or, in the case of extreme conflict, flip this positive association to negative. Although highly committed individuals should also be inclined to undermine the partner's personal interests that are inherently destructive to the relationship (e.g., extra-relationship affairs) to protect the relationship, we focus on situations in which the partner's specific personal interests hurt or misalign with the relationship's interests incidentally rather than by design (e.g., studying abroad). In such situations, individuals might still experience a relationship threat posed by the partner's interests, even 
though they may not additionally perceive that their partner's pursuit of these interests implies the partner's lack of commitment to the relationship.

Highly (vs. less) committed individuals tend to be more active in coping with threats to the relationship present in social situations (e.g., the presence of attractive romantic alternatives) to the extent that the levels of these relationship threats escalate (e.g., D. J. Johnson \& Rusbult, 1989; Lydon et al., 2003). By the same token, we suggest that the well-established finding that highly committed individuals support and promote their partner's interests is strongest in situations where those interests do not threaten the relationship and the support can indirectly benefit the relationship (see Figure 1) —a commitment $\times$ relationship threat interaction effect. When the pursuit of this particular partner interest poses threats to the relationship, pro-partner behaviors that support this interest may actually harm the relationship more than benefit it. In such conflict situations, highly committed individuals may, to protect the relationship, reduce their typical tendency to engage in pro-partner behaviors, whereas less committed individuals may be less influenced by relationship threat. We refer this phenomenon as "the Manhattan effect."

As in Figure 1, the extent to which highly committed individuals reduce their intentions to engage in pro-partner behaviors is largely determined by the perceived level of relational threat posed by the partner's interests. In the extreme case where the partner's interests are perceived as an existential threat to the relationship that can lead to relationship dissolution, highly committed individuals may even undermine their partner's interests in order to protect the relationship, as when Isaac, once he became strongly committed to the relationship, tried to prevent Tracy from studying abroad. In contrast, given that less committed individuals tend to be neither partner-oriented nor relationship-oriented, their level of support for their partner's personal interests will be less influenced by the level of threat the specific interest may pose to the relationship.

\section{Overview of the Studies}


In short, the present research re-examines the influence of relationship commitment on propartner behaviors by emphasizing the distinction between the partner's and the relationship's interests. In Studies 1a and 1b, we sought to provide initial evidence that goal-pursuit that is oriented toward benefitting the partner typically, but not always, also is oriented toward benefiting the relationship. To test this idea, we asked participants to list their specific personal goals, and then reported the extent to which these goals serve the interests of the relationship and the partner. Given that the study sampled a wide range of goals of which both the partner's interests and the relationship's interests would or would not be the central concerns, it allowed us to assess the natural link between the partner's interests and the relationships' interests in everyday life. More importantly, we examined the extent to which highly versus less committed individuals are more likely to prioritize behaviors that promote either the partner's or the relationship's interests. By separating the partner's and the relationship's interests, we tested the hypothesis that relationship commitment would be an important predictor of behavior oriented toward the relationship's interest, but perhaps less so for predicting behavior oriented toward the partner's interests.

Then, after demonstrating that the partner's and the relationship's interests are naturally overlapping and yet separable in the two initial studies, we conducted seven additional studies to investigate the effects of commitment on support for the partner's interests in the face of the partnerversus-relationship conflicts (the Manhattan effect). These studies examined both real events from participants' lives (Studies 2b and 3) and standardized scenarios (Studies 2a, 4, 5a, 5b, and 6). Whereas real-life events provided ecological validity for our predictions, standardized scenarios allowed us to eliminate extraneous factors that are otherwise present in real-life interpersonal situations, and also allowed us to investigate extreme relationship threats that may be practically and ethically impossible to study through other means. In Studies 2a, 2b, and 3, we examined how the presence versus absence of high relationship threats may reduce highly committed individuals' motivations to support their 
partner's personal interests. Moreover, we further examined how strongly a relationship threat could potentially alter the association between relationship commitment and pro-partner behaviors. Specifically, in Studies 4, 5a, 5b, and 6, we employed scenarios in which a partner's pursuit of his or her personal interests poses a severe, existential threat to the relationship (i.e., relationship dissolution), testing whether highly (versus less) committed individuals would further reduce their willingness to support their partner's personal interests and the joint interests of both parties. In these seven studies, given that we were interested in the effects of misalignment of the partner's and the relationship's interests, we did not consider relational transgressions that are inherently destructive to the relationship (e.g., infidelity). Although we believed that our predictions also apply to such destructive relational behaviors, unsupportive responses in such situations are likely to be influenced by a broader range of motivations (e.g., retaliatory goals).

In all studies that assessed relationship commitment with self-reports (except Study 3, which focused on daily fluctuations of relationship commitment and therefore required an abbreviated measure), we employed standardized, widely used measures from the literature of interdependence analysis (Arriaga \& Agnew, 2001; Rusbult, Martz, \& Agnew, 1998). Given that such self-report measures captured the aspects of relationship commitment based on personal attraction to or the intrinsic value of the relationship, we also controlled for relationship satisfaction in the seven studies that assessed that construct (Studies 1a, 1b, 2a, 3, 4, 5b, and 6). Such analyses allowed us to examine whether the effects of relationship commitment would remain robust after controlling for relationship satisfaction (Rusbult, 1980). In addition, to allow for causal conclusions, we complemented our selfreport assessments of relationship commitment in Studies 1a, 1b, 2a, 2b, 3, 4, and 5a with experimental manipulations of it in Studies $5 \mathrm{~b}$ and 6.

\section{Study 1a: Priorities in Goal Pursuit}


We had two goals in conducting Studies $1 \mathrm{a}$ and $1 \mathrm{~b}$ before directly examining the proposed Manhattan effect. First, we wanted to show that concerns for the partner's interests and for the relationship's interests in goal-directed behaviors are separable. It is not surprising to observe a strong correlation between the partner-oriented and relationship-oriented concerns. However, this correlation should not be perfect given the possibilities of conflicts between these two interests. Second, and more importantly, we examined whether highly versus less committed individuals might prioritize goals that are oriented toward the partner's interests or the relationship's interests, or both. We anticipated that specific actions oriented toward the partner's interests would, on average, also be oriented toward the relationship's interests, but that, when (statistically) separating these two motivations, relationship commitment would be more important for predicting behavior uniquely oriented toward the relationship's interests, but less so for predicting behavior uniquely oriented toward the partner's interests.

In Study 1a, we first assessed participants' relationship commitment and satisfaction. We then asked participants to list their 10 most important goals. Participants then reported the extent to which they pursued each of the 10 goals for their self-interests, the partner's interests, and the relationship's interests, and the extent to which they prioritized each goal.

\section{Method}

Participants and procedures. A total of 205 participants ( 119 females, $M_{\text {Age }}=30.95, S D=$ 9.95) in the United States who reported being involved in an exclusive relationship participated in the study administered on the Amazon Mechanical Turk (mTurk) website (Buhrmester, Kwang, \& Gosling, 2011; Paolacci, Chandler, \& Ipeirotis, 2010). One hundred and one participants were married, and the average relationship length was 8.61 years $(S D=29.58)$.

In this study and the remaining studies that employed mTurk for data collection, potential participants first reported their mTurk Worker ID number in the online questionnaire. They were only 
allowed to proceed if their Worker ID number did not match with those of the participants who had participated in any related studies. In each study, we also administrated an instructional manipulation check (Oppenheimer, Meyvis, \& Davidenko, 2009) to ensure that participants closely followed instructions. Data from participants who failed to correctly respond to this manipulation check were not included in the data analysis.

Measures. Participants were first asked to list the 10 most important goals they wanted to pursue now and in the future. After listing these goals, participants reported (a) how much effort they wanted to invest in each goal and (b) how much they wanted to pursue each goal at the expenses of other goals including those not listed. These two items were averaged to capture the extent to which each goal was a high priority $(\alpha=.84)$. They then reported the degree to with they were trying to accomplish each goal for (a) their own interests, (b) their partner's interests, and (c) their relationship's interests $(1=$ not at all to $9=$ extremely $)$. Finally, participants completed a 12 -item relationship commitment measure (e.g., "I intend to stay in this relationship"; $1=$ do not agree at all to $5=$ completely agree; $\alpha=.88$; Arriaga \& Agnew, 2001) and a 5-item relationship satisfaction measure ("I feel satisfied with our relationship"; $1=$ strongly disagree to $5=$ strongly agree; $\alpha=.92$; Rusbult et al., 1998).

\section{Results and Discussion}

Data-analytic strategy. The data provided by a given individual across the 10 goals in the study were not independent. As such, the Study 1a design included two levels of nesting - the data from reports for each goal were nested within individuals. Therefore, we used hierarchical linear modeling to analyze our data, using the SPSS Mixed procedure (Peugh \& Enders, 2005).

We centered each of the three key lower-level predictors (i.e., relevance of the goal to selfinterests, partner's interests, and relationship interests) around each individual's mean for that predictor across the 10 goals. Next, we conducted multilevel hierarchical analyses to test the fixed effects of our 
predictors. We first entered the two person-level predictors (relationship commitment and satisfaction) and the three within-person-level predictors (i.e., self-interests, partner's interests, and relationship interests) to examine the associations of these predictors with the dependent variable (i.e., priorities for each goal). To test our core hypotheses, we then entered six interaction terms: commitment $\times$ selfinterests, commitment $\times$ partner's interests, commitment $\times$ relationship's interests, satisfaction $\times$ selfinterests, satisfaction $\times$ partner's interests, and satisfaction $\times$ relationship's interests.

All analyses were performed representing both intercepts and slopes for key predictors as random effects, allowing within-person-level predictors to vary randomly across individuals. When tests examining the variance and covariance components revealed nonsignificant between-individual differences in slopes, we recalculated models representing slopes as fixed effects.

Analyses. At the within-person level, a goal highly relevant to partner's interests tended to be also highly relevant to relationship's interests $(r=.67)$. A goal highly relevant to self-interests did not seem to have strong relevance to partner's interests $(r=.12)$ or relationship's interests $(r=.17)$. The analyses were consistent with our predictions. Across all studies, we did not observe any systematic interactions involving gender or marital status, so we dropped these factors from analyses.

The results of multilevel analyses were summarized in Table 1. Consistent with our predictions, the commitment $\times$ relationship's interests interaction effect on ratings of the priority of a given goal was significant, and the commitment $\times$ partner's interests interaction effect was not. Moreover, relationship satisfaction did not show any moderating effects. ${ }^{1}$

We then unpacked the commitment $\times$ relationship's interests interaction effect. As depicted in Figure 2, simple-slope analyses (Aiken \& West, 1991) revealed that highly committed individuals (+1

\footnotetext{
${ }^{1}$ Given the high correlation between the two indices of partner's interests and relationship's interests in Studies $1 \mathrm{a}$ and $1 \mathrm{~b}$, we re-ran the analyses by only including one index each time. In other words, in the multilevel analyses, we entered relationship commitment and satisfaction plus one index of the interests (partner's or relationship's interests) and the two commitment $\times$ interests and satisfaction $\times$ interests interactions. Across both studies, the results yielded the same conclusions: the commitment $\times$ relationship's interests interaction was significant $(p s<.04)$, but all the other interactions were nonsignificant $(p s>.33)$
} 
$S D$ ) reported that a given goal was a higher priority when it was more (vs. less) relevant to the relationship's interests, $\beta=.31, t=5.40, p<.001$. Less committed individuals $(-1 S D)$ showed the same tendency, but to a lesser extent, $\beta=.12, t=2.10, p=.04$. The association of relationship commitment with a given goal's priority trended nonsignificantly in a negative direction when the goal was less relevant to the relationship's interests $(-1 S D), \beta=-.10, t=-1.19, p=.23$. However, it trended nonsignificantly in the opposite direction when the goal was more relevant to the relationship's interests $(+1 S D), \beta=.09, t=1.19, p=.24$.

In sum, Study 1a yielded two important insights. First, as expected, although partner-oriented and relationship-oriented concerns in goal pursuit tended to be highly correlated, they were separable. Second, and more importantly, when these two types of interests were statistically separated, relationship commitment predicted a stronger association of the relationship's interests with a goal's relative priority to the individual. In contrast, relationship commitment did not predict a stronger association of partner's interests with a goal's relative priority. Moreover, the moderating effect of relationship commitment was robust even after controlling for the effects of relationship satisfaction. Thus, the findings suggest that relationship commitment predicts the prioritization of goals that promote relationship interests, not goals that promote partner interests.

\section{Study 1b: Actual Efforts in Daily Goal Pursuit}

Study $1 \mathrm{~b}$ sought to replicate the findings in Study 1a with an intensive experience-sampling procedure. In this study, we assessed participants' relationship commitment and satisfaction in an initial session and then examined their actual daily goal pursuit over the course of a week. In each instance of experience-sampling, participants reported the extent to which they pursued a current goal for the self's interests, the partner's interests, and the relationship's interests, and the extent to which they invested efforts in the specific goals.

\section{Method}


Participants. Participants were both partners from 115 heterosexual couples $($ mean age $=$ 24.03, $S D=4.80$ ) who were recruited via advertising in local newspapers in the larger Chicago metropolitan area. They had been romantically involved in an exclusive relationship for an average of 31.06 months $(S D=33.89)$.

Procedures. Participants registered for a large experience-sampling study that examined the influence of self-regulation in close relationships (Hofmann, Finkel, \& Fitzsimons, 2013). Recruitment ads pointed to an online screening survey for the study. Couples were eligible if both partners indicated they were in an exclusive romantic relationship and if they had been together for at least 3 months; in addition, they both needed to be older than 18 years of age, proficient in English, and in possession of a smartphone including a touchscreen, texting capability, and a data plan.

Participants attended a laboratory-based session together as a couple for an orientation meeting and pretest assessment. At this session, a trained experimenter informed the participants about the general purpose of the study, providing both oral and written instructions and rules regarding the mobile phase of the study (including a short survey demonstration on participants' smartphone). Participants then registered their phone in the mobile phase of the survey via a web-application (surveysignal.com; Hofmann \& Patel, 2013) that had been programmed for the purpose of this study with the help of a professional programmer. They then completed a series of intake measures.

Of particular relevance to the present article, they reported their relationship commitment on a 7-item scale (e.g., "I want our relationship to last a very long time"; Rusbult et al., 1998; $\alpha=.89$ ) and their relationship satisfaction on a 5-item scale (used in Study 1a; Rusbult et al., 1998; $\alpha=.90$ ). Participants responded to these items using 7 -point scales $(1=$ strongly disagree to $7=$ strongly agree $)$.

Experience-sampling records. In the experience-sampling phase, six daily signals were randomly distributed via smartphone between 9 a.m. and 8 p.m. Participants were asked to respond to these signals for one week. Therefore, each participant could provide up to 42 records throughout the 
experience-sampling period. Daily signals within each dyad were yoked such that both partners received their signals at the same time. Participants were instructed to respond to a brief survey within three hours after receiving each daily signal. In each survey, participants first indicated whether they were trying to accomplish something right now. If the participants indicated "Yes", they briefly described what they were trying to accomplish and then rated the degree to with they were trying to accomplish it for (a) their own interests, (b) their partner's interest, and (c) their relationship's interests. Finally, they also reported how much effort they were investing to accomplish the goal. They responded to these items using 7 -point scales $(0=$ not at all to $6=$ very much $)$.

\section{Results and Discussion}

Data used for analyses. All 230 participants completed the pretest assessment. Six participants dropped out of the mobile phase due to technical problems with their smartphone that could not be solved quickly. We further dropped 13 participants who gave fewer than five records that consisted of complete responses to all key measures of interest. These exclusions yielded a final sample of 211 participants who on average completed 21.33 records.

Data-analytic strategy. The data provided by a given individual across the experiencesampling records were not independent, and the data provided by the two partners in a given relationship were not independent. As such, the Study $1 \mathrm{~b}$ design included three levels of nesting-the data from multiple diary reports were nested within individuals and the data from two individuals in a given relationship were nested within couple. Therefore, we used multilevel modeling to analyze our data, using the SPSS Mixed procedure. Specifically, we closely followed the statistical procedures proposed by Bolger and Laurenceau (2013) to treat the three levels of our dyadic longitudinal data (observations nested within persons nested within couples). To control for any systematic effects of (linear) temporal trends, time was entered as a predictor. We centered the three key lower-level predictors (i.e., goal relevance to self-interests, partner's interests, and relationship interests) around 
each individual's mean across the all experience-sampling observations. Across all participants, time was centered around the midpoint of the experience-sampling period.

We first entered the two person-level predictors (relationship commitment and satisfaction) and the four within-person-level predictors (i.e., self-interests, partner's interests, relationship interests, and time) to examine the associations of the predictors with the dependent variable (i.e., effort invested in the goal). To test our core hypotheses, we then entered six interaction terms: commitment $\times$ selfinterests, commitment $\times$ partner's interests, commitment $\times$ relationship's interests, satisfaction $\times$ selfinterests, satisfaction $\times$ partner's interests, and satisfaction $\times$ relationship's interests. In all fixed-effects analyses, given that we had no relevant hypotheses, we did not examine partner effects.

In addition, all analyses were performed representing both intercepts and slopes for key predictors as random effects, allowing within-person-level predictors to vary randomly across individuals and across couples. We also specified the autocorrelations between two temporally consecutive observations to reduce the chance of Type-I errors (Bolger \& Laurenceau, 2013). When tests examining the variance and covariance components revealed nonsignificant between-individual and between-couple differences in slopes, we recalculated models representing slopes as fixed effects. Given that we were not interested in the gender effect, we only specified gender in the random effects to distinguish the members within a dyad.

Analyses. At the within-person level, a goal highly relevant to partner's interests tended to be also highly relevant to relationship's interests $(r=.82)$. A goal highly relevant to self-interests did not seem to have strong relevance to partner's interests $(r=.03)$ or relationship's interests $(r=.05)$. The analyses were consistent with our predictions and the findings in Study 1a (also see Footnote 1).

The results of multilevel analyses are summarized in Table 2. Consistent with our predictions, the results revealed that the commitment $\times$ relationship's interests interaction effect on efforts in goal 
pursuit was significant. The commitment $\times$ partner's interests interaction effect was not. Moreover, relationship satisfaction did not show any moderating effects. ${ }^{2}$

We then unpacked the commitment $\times$ relationship's interests interaction effect. As depicted in Figure 3, simple-slope analyses revealed that highly committed individuals $(+1 S D)$ invested more effort when the current goal was more (vs. less) relevant to the relationship's interests, $\beta=.18, t=$ 4.56, $p<.001$, whereas less committed individuals $(-1 S D)$ showed the same, albeit nonsignificant, tendency, $\beta=.04, t=.89, p=.37$. In addition, the association of relationship commitment with effort was nonsignificant when the current goal was less relevant to the relationship's interests than typical ($1 S D), \beta=-.00, t=-.03, p=.98$. However, the association was significant and positive when the current goal was more relevant to the relationship's interests than typical $(+1 S D), \beta=.14, t=2.75, p<$ .01 .

In sum, using experience-sampling procedures, the results of Study $1 \mathrm{~b}$ converged cleanly with those of Study 1a. First, again, although partner-oriented and relationship-oriented concerns in goal pursuit tended to be highly correlated, they were separable. Second, and more importantly, when these two types of interests were statistically separated, relationship commitment predicted a stronger association of the relationship's interests with a goal's relative priority to the individual. In contrast, relationship commitment did not predict a stronger association of partner's interests with a goal's relative priority. Moreover, the moderating effect of relationship commitment was robust even after controlling for the effects of relationship satisfaction.

The lack of significant commitment $\times$ partner's interests interactions across Studies 1a and 1b is consistent with our conceptual analysis that relationship commitment might be more important for predicting behaviors that were oriented toward the relationship's interests than for predicting behaviors

\footnotetext{
${ }^{2}$ We also observed an unpredicted commitment $\times$ self-interest interaction. Given that this effect was not central to our predictions and did not replicate in Study 1a, we did not further explore it.
} 
uniquely oriented toward the partner's interests. Still, given the possibility that, in these two studies, the goals in question might be generally less consequential to the partner's outcomes, an alternative explanation is plausible: highly (vs. less) committed individuals might have truly elevated partneroriented concerns but did not reveal these concerns in the pursuit of daily goals, as these goals were only mildly beneficial to the partner's interests. To rule out this alternative explanation, in subsequent studies, we examined interpersonal situations in which one's behavior can clearly and substantially benefit the partner's interests but potentially conflict with the relationship's interests. These studies allowed direct examination of whether relationship commitment truly promotes the partner's interests when these interests no longer align with the relationship's interests.

\section{Study 2a: Support for the Partner's Personal Interests under Relationship Threat}

Thus far, Studies 1a and 1b demonstrated that when individuals pursue personal goals, their concerns for the partner's interests and concerns for the relationship's interests in the goal pursuit tended to be highly correlated but still separable. Despite the evidence that individuals tended to typically pursue goals simultaneously for the partner's and the relationship's interests, it is still plausible that people encounter interpersonal conflicts that often involve misalignment of the partner's and the relationship's interests. ${ }^{3}$ In such situations, individuals have to prioritize their concerns for one of these two interests over their concerns for the other. The seven studies reported below examined such instances, which allowed for direct tests of the Manhattan effect.

\footnotetext{
${ }^{3}$ To support this assumption, we conducted an mTurk pilot study with a sample of 73 U.S. residents who reported being in an exclusive relationship (42 females, 41 married, $M_{\text {Age }}=32.71, S D=11.33$ ). Participants were asked to report on five conflicts that they experienced in their relationship over the previous two weeks. In total, participants listed 354 conflicts. Participants then categorized each conflict they listed into one of the four categories: (a) conflicts between their partner's personal interests and the relationship's interests $(19.5 \%)$, (b) conflicts between their own personal interests and the relationship's interests $(13.3 \%)$, (c) conflicts between their own and their partner's personal interests (54.8\%), or (d) other kinds of conflicts (12.4\%). In general, the partner-versus-relationship conflicts included "not enough time at home" and "future planning, she never discusses about it, she is so busy, never thinks about it." Only a small subset of these conflicts ( $10.0 \%$ or $2.0 \%$ of all conflicts) involved behaviors that were unambiguously destructive to the relationship (e.g., "lying," and "he is flirty with other girls, and it makes me feel threatened"). In short, conflicts between the partner's personal interests and the relationship's interests appear to be a common type of conflicts in adults' romantic relationships.
} 
In Studies 2a, 2b, and 3, and 4 we either manipulated or assessed the degree of conflict between the partner's interests (hobbies and goals in these cases) and the relationship's interests, which allowed for direct tests of whether this conflict can reduce highly committed individuals' intentions to engage in pro-partner behaviors. In Study 2a, which was inspired by the Isaac-and-Tracy example from Manhattan, some of the participants confronted a hypothetical situation where the partner's goal pursuit was not especially threatening to the relationship (i.e., studying in the local area), whereas others confronted a hypothetical situation where the partner's goal pursuit was more threatening (i.e., studying abroad).

Studies 1a and $1 \mathrm{~b}$ had shown that relationship commitment is reliably linked to behaviors motivated by the relationship's interests, but not to behaviors motivated by the partner's interests, which suggests that relationship commitment is predominantly relationship-oriented. In line with these findings and our earlier theorizing, we predicted that relationship commitment would predict greater willingness to support the partner's hobby when relationship threat is mild, but that this effect would become weaker, perhaps even disappearing or reversing, as the relationship threat becomes more severe. We also included a measure of relationship satisfaction and predicted that the commitment $\times$ threat interaction would remain robust even with the satisfaction $\times$ threat interaction in the model.

\section{Method}

Participants. One hundred and fifty-seven mTurk volunteers in the United States (58 females, $\left.M_{\text {Age }}=26.87, S D=7.49\right)$ participated in the study. All were in an exclusive relationship. Forty-two participants were married, and the average relationship length was 4.98 years $(S D=5.88)$.

Procedures. Participants were first randomly assigned to immerse themselves in one of the two scenarios-one that was mildly or one that was moderately threatening to the relationship. Participants first nominated one skill-required hobby or interest that their partner possessed but they did not share. Participants then read that their partner wanted to increase expertise in this domain and applied for 
training programs both in the local area and other countries to advance the personal interest. In the low threat condition, participants read that their partner was only accepted by one training program and that the program was just several miles away from where the couple lived. In the high threat condition, participants read that their partner was only accepted by one training program, that this program was in another country, and that, due to other obligations, the participants could not move abroad with their partner.

\section{Measures.}

Decision-making task. Participants then read that the partner was eager to learn how to advance the hobby further and thought that the training program would be very helpful. They also read that the partner was about to enroll into the program, but wanted the participants' input before committing. Participants then responded to a 6-point scale $(1=$ Very likely I am going to support my partner's inclination to enroll into the program, $6=$ Very likely I am going to discourage my partner from enrolling into the program). In addition, participants answered two more questions on 6-point scales $(1=$ very likely to $6=$ very unlikely): "How likely would you want to share the financial costs with your partner?", "How likely would you want to compromise the time spent together to let your partner enroll into the program?" The three items were reverse-coded such that higher score indicated stronger intentions to support the partner's pursuit of personal hobby $(\alpha=.66)$.

Manipulation check. Participants then answered two questions $(1=$ not at all, to $5=$ extremely): "How much do you think that the relationship will have a lot of problems if your partner enrolls in the program?" and "How much do you think that the relationship will end if your partner enrolls in the program?" $(\alpha=.90)$.

Relationship commitment and satisfaction. Participants filled out a 12-item relationship commitment scale $(\alpha=.93$; Arriaga $\&$ Agnew, 2001) and a 5-item relationship satisfaction scale $(\alpha=$ .92 ; Rusbult et al., 1998). 


\section{Results and Discussion}

Manipulation check. Participants in the high $(M=2.61, S D=1.33)$ versus the low $(M=1.56$, $S D=.79)$ threat condition indicated to a larger extent that educational opportunity was a threat to their relationship, $F(1,155)=34.05, p<.001$, which suggests that the manipulation was successful. In addition, threat manipulation did not affect relationship commitment and satisfaction, $F \mathrm{~s}<1.42, p \mathrm{~s}>$ .23 .

Hypothesis testing. We conducted a hierarchical regression analysis on intentions to support the partner's pursuit of the personal hobby, with standardized commitment and satisfaction scores and contrast-coded variable of threat condition $(-1=$ low threat and $1=$ high threat $)$ entered into the first step and the commitment $\times$ threat and satisfaction $\times$ threat interaction into the second step. Consistent with our hypotheses, the results presented in Table 3 revealed that the commitment $\times$ threat interaction effect was significant and that the satisfaction $\times$ threat interaction was not.

As depicted in Figure 4, simple-slope analyses revealed that the association of relationship commitment with intentions to support the partner was significant and positive in the low threat condition, $\beta=.31, t(151)=2.12, p=.04$, but it trended nonsignificantly in the opposite direction in the high threat condition, $\beta=-.15, t(151)=-.97, p=.33$. In addition, highly committed individuals $(+1$ $S D)$ exhibited weaker intentions to support the partner in the high versus the low threat condition, $\beta=-$ $.60, t(151)=-4.68, p<.001$, but this association was nonsignificant among less committed individuals $(-1 S D), \beta=-.14, t(151)=-1.10, p=.28$.

Thus, using a controlled hypothetical scenario, these findings showed that the conflict between the partner's and the relationship's interests can moderate the association of relationship commitment with pro-partner inclinations. When the partner's interests do not pose a relationship threat, highly committed individuals have stronger intentions to support their partner than do less committed 
individuals. In contrast, when the partner's interests do pose relationship threat, highly and less committed individuals report about equally weak intentions to support their partner.

\section{Study 2b: Support for the Partner's Personal Interests under Relationship Threat}

Study $2 \mathrm{~b}$ extended Study 2a by testing the same set of hypotheses in real-life dilemmas (rather than scenarios) involving conflicts between the partner and the relationship. In Study $2 b$, participants were asked to recall an unresolved, recent conflict between the partner's personal interests and the relationship's interests. They then assessed how threatening the conflict was to the relationship and indicated their intentions to support their partner's interests in this situation.

\section{Method}

Participants. Fifty-one mTurk volunteers in the United States (28 females, $M_{\text {Age }}=28.67, S D=$ 8.66) participated. All were in an exclusive relationship. Eighteen participants were married, and the average relationship length was 4.03 years $(S D=4.40)$.

Procedures. Participants were first asked to describe an unresolved relationship conflict in the past two weeks that involved the partner's long-term personal interests outside the relationship and the interests of the relationship (e.g., "My partner's work schedule is conflicting with our schedule," "She wants to move away for two years to accept an internship.”).

Participants then responded to two items assessing how threatening the conflict was to the relationship ( $\alpha=.68$ ): "How much do you think that this conflict creates a threat to your relationship?" $(1=$ not at all to $9=$ very $m u c h)$ and "In this situation, how would you characterize the relationship between your partner's personal interests and the interests of the relationship?" (1 = These interests are highly compatible with each other to $9=$ These interests are highly incompatible with each other).

Next, they responded to two items assessing their intentions to support the partner's interests in this conflict $(1=$ not at all to $9=$ very $m u c h)$ : "How much would you compromise to maximize your 
partner's personal interests in this conflict?" and "How much would you do to support your partner's personal interests in this conflict?" $(\alpha=.80)$.

Relationship commitment. Finally, participants filled out a 12-item relationship commitment scale ( $\alpha=.86$; Arriaga \& Agnew, 2001). This study did not include a measure of relationship satisfaction.

\section{Results and Discussion}

Preliminary analyses. None of the participants listed any conflicts that were unambiguously destructive to the relationship (e.g., infidelity). Preliminary analyses of the two relationship threat items showed that the reported conflicts involved moderate incompatibility between the partner's and the relationship's interests $(M=5.92$ versus the neutral midpoint of $5, t(50)=2.91, p<.01)$ and created a moderate threat to the relationship $(M=6.13$ versus the midpoint of $5, t(50)=3.29, \mathrm{p}<.01)$. Relationship commitment and relationship threat were negatively correlated, $r(51)=-.25, p=.08$.

Hypothesis testing. We conducted a hierarchical regression analysis on intentions to support the partner's interests, with standardized scores of relationship commitment and relationship threat entered into the first step and their interaction into the second step. Consistent with our hypotheses, the results presented in Table 4 revealed that the commitment $\times$ threat interaction effect was significant.

As depicted in Figure 5, simple-slope analyses revealed that the association of relationship commitment with intentions to support the partner was significant and positive for participants who reported a low-threat conflict $(-1 S D), \beta=.48, t(47)=2.19, p=.03$, but it trended nonsignificantly in the opposite direction for participants who reported a high-threat conflict $(+1 S D), \beta=-.26, t(47)=-$ $1.60, p=.12$. In addition, highly committed individuals $(+1 S D)$ exhibited weaker intentions to support the partner when they reported high (vs. low) threat conflicts, $\beta=-.59, t(47)=-3.49, p=.001$; this association was nonsignificant among less committed individuals $(-1 S D), \beta=.15, t(47)=.72, p=.48$. These results were consistent with our findings in Study 2a. 
Taken together, whether focusing on a specific, well-controlled partner interest (the educational opportunity in Study 2a) or on a wide variety of naturally occurring partner interests (Study 2b), the conflict between such interests and the relationship's interests moderated the association of relationship commitment with pro-partner inclinations. When the partner's interests do not pose a relationship threat, highly committed individuals have stronger intentions to support their partner than do less committed individuals. In contrast, when the partner's interests do pose relationship threat, highly and less committed individuals report equally weak intentions to support their partner.

\section{Study 3: Daily Support for the Partner's Goal Pursuit under Relationship Threat and Personal Threat}

In Study 3, we employed a daily diary approach to examine how these processes play out in everyday interactions between partners. Each partner's pursuit of personal interests in day-to-day life has the potential to threaten both the other partner's interests (e.g., own happiness and personal goal pursuits) and the interests of the relationship (e.g., time spent together). These two distinct types of threat may differentially affect an individual's support for the partner's goals, when he or she has relatively high or low relationship commitment on a given day. We predicted that individuals who were more versus less committed on a given day would be more willing to support their partner's personal goal pursuit when that pursuit threatens their self-interests, but not when it threatens their relationship's interests. That is, Study 3's daily diary procedures allowed us to predict support for the partner's personal goal-pursuit on a given day from within-person daily fluctuations in relationship commitment, relationship threat associated with that goal-pursuit, and personal threat associated with that goal-pursuit. Prior research suggests that relationship commitment fluctuates to some degree from one day to the next (e.g., Knee, Patrick, Vietor, \& Neighbors, 2004; Murray et al., 2009; Slotter et al., 2012), and we sought to leverage this fact to test whether different levels of daily relationship and 
personal threat would moderate the association between daily relationship commitment and daily support for the partner's personal goal pursuit.

Beyond allowing for tests in everyday life of the hypothesis regarding relationship threat supported in Studies 2a and 2b, Study 3 also allowed us to examine how personal threat may undermine support for the partner's goal-pursuit. Previous research has shown that less versus highly committed individuals prioritized self-interests to a larger degree (Van Lange, Agnew, et al., 1997; Van Lange, Rusbult, et al., 1997), suggesting that personal threat rather than relationship threat may be more powerful in undermining less committed individuals' support for their partner's goal pursuit. In contrast, given that highly versus less committed individuals downplay their self-interests, personal threat should not affect highly committed individuals' motivations to support their partner's goal pursuit. To test this prediction, we examined whether daily fluctuation in personal threat would also moderate the association between daily relationship commitment and support for the partner's personal goal pursuit on a given day.

Given our interest in the association between support of specific daily goals with the levels of the two potential threats these goals might incur on a given day and the moderation of relationship commitment on the same day, we focus on the within-day interaction effects involving these variables.

\section{Method}

Participants. Participants were both partners from 92 couples (91 heterosexual couples, 1 lesbian couple, mean age $=22.07, S D=3.62$ ) who were recruited via notices posted around the community and in local newspapers. They had been romantically involved for an average of 22.31 months $(S D=18.24)$, and most were steadily dating (91\% dating steadily, $6 \%$ engaged or married, $3 \%$ other).

Procedures. Participants were informed that the study concerned the pursuit of personal life goals by partners in ongoing relationships (Kumashiro, Rusbult, \& Finkel, 2008). They were given 
packets including daily diary records, along with addressed, stamped envelopes for use in returning completed records. They were asked to complete a diary record at about the same time each evening describing their experiences during that day. If they were unable to complete the record on a given evening, they were asked to do so as soon as possible the next morning. Participants were asked not to speak with their partners about their records. Completed diary records were returned following Days 4 , 7, and 10. At the end of the 10-day period, participants completed an exit questionnaire that inquired about the reliability and validity of the data they provided (e.g., did they complete diary records each evening, were they actually romantically involved with the partners with whom they participated?).

Daily diary records. Items relevant to our research were distributed throughout the diary record form, interspersed with items designed to assess other constructs (e.g., life satisfaction). All items were responded on 5-point scales $(1=$ do not agree at all, $5=$ agree completely $)$. The records included a two-item, face-valid measure of relationship commitment ("I felt very committed to maintaining my relationship with my partner" and "I felt that I really want our relationship to persist"; $\alpha=.94$ ) and a one-item measure of relationship satisfaction ("I felt good about our relationship).

Participants were asked to list their partner's goals for that day. They then responded to items regarding their assessment of and support for the partner's goal pursuit. Relational threat caused by the partner's goal pursuit was measured by two items ("My partner's pursuit of his/her goals caused problems for our relationship (e.g., made it hard to spend time together)" and "My partner's pursuit of his/her goals created conflict in our relationship (e.g., differences of opinion, arguing)"; $\alpha=.79$ ), whereas personal threat caused by the partner's goal pursuit was measured by a single item ("My partner's pursuit of his/her goals created difficulties for me (was unpleasant, made me feel bad, required giving up activities that I care about)"). Actual support for the partner's goal-pursuit was measured by four items ("I conveyed approval of my partner and his/her goal pursuits", "I showed that I really wanted my partner to achieve his/her goals", "I complained about (or expressed dissatisfaction 
with) my partner's goal pursuits" (reversed), and "I was not supportive of my partner's goal pursuits" (reversed); $\alpha=.68)$.

\section{Results and Discussion}

Data used for analyses. Of the 184 individuals (92 couples) who participated in the study, we obtained usable data from 131 individuals of them because (a) 12 people failed to return their diary records despite repeated reminders, (b) 10 people admitted in the exit questionnaire that they were not romantically involved (they took part to earn money), (c) 10 people admitted in the exit questionnaire that their records were not particularly accurate, (d) 19 people did not report all the key questionnaires for at least 5 times across the 10-day study, and (e) our statistical models (which required distinguishable data) required jettisoning data from one lesbian couple. The 131 individuals completed nearly all of their interaction records $(M=9.31)$. None of the participants listed any goals that were unambiguously destructive to the relationship. ${ }^{4}$

Data-analytic strategy. The data provided by a given individual across days of the study were not independent, and the data provided by the two partners in a given relationship were not independent. As such, the Study 3 design included three levels of nesting — the data from multiple diary reports were nested within individuals and the data from two individuals in a given relationship were nested within couple. Therefore, as in Study 1b, we used multilevel modeling to treat the three levels of our dyadic longitudinal data (observations nested within persons nested within couples). Again, to control for any systematic effects of (linear) temporal trends, time was entered as a predictor. We first centered the four key within-person-level predictors (i.e., relationship commitment, relationship satisfaction, relationship threat, and personal threat) around each individual's mean across observations. Across all participants, time was centered around the midpoint of the daily diary period.

\footnotetext{
${ }^{4}$ Preliminary analyses on the intake measures showed that participants included in the study $(n=131)$ did not differ from excluded participants (who were truly romantically involved; $n=43$ ) in term of their age, gender, and baseline measure of relationship commitment (Arriaga \& Agnew, 2001), all $p \mathrm{~s}>40$.
} 
We conducted multilevel hierarchical analyses to test the fixed effects of our predictors. We first entered all within-person-level predictors (i.e., commitment, satisfaction, relationship threat, personal threat, and time) and examined the associations of the predictors with the dependent variable (i.e., support for partner's goal). To test our core hypotheses, we then entered four interaction terms: commitment $\times$ relationship threat, commitment $\times$ personal threat, satisfaction $\times$ relationship threat, and satisfaction $\times$ personal threat. In all fixed-effects analyses, we did not examine the partner effects.

In addition, all analyses were performed representing both intercepts and slopes for key predictors as random effects, allowing Level 1 predictors to vary randomly across individuals and across couples. As in Study 1b, we further specified the autocorrelations between two consecutive observations to reduce the chance of Type-I errors. When tests examining the variance and covariance components revealed nonsignificant between-individual and between-couple differences in slopes, we recalculated models representing slopes as fixed effects. Given that we were not interested in the gender effect, we again only specified gender in the random effects to distinguish the members within a dyad.

Preliminary analyses. At the within-person level, a partner's daily goal that posed relationship threat also tended to pose personal threat $(r=.58)$. Daily relationship commitment was only weakly-tomoderately related to relationship threat $(r=-.21)$ and personal threat $(r=-.17)$ posed by the partner's daily goal, suggesting that people's daily levels of relationship commitment were modestly related to how they assessed the potential threat posed by the partner's daily goal.

Hypothesis testing. The results of multilevel analyses are summarized in Table 5. Consistent with our hypotheses, the results revealed that the commitment $\times$ relationship threat interaction effect and the commitment $\times$ personal threat interaction effect were significant and in opposite directions. ${ }^{5}$

\footnotetext{
${ }^{5}$ As we also assessed baseline relationship commitment in the intake session, we examined whether the stable individual difference in relationship commitment moderated the effects of personal and relational threat. The commitment $\times$
} 
We first unpacked the commitment $\times$ relationship threat interaction effect. As depicted in Figure 6, simple-slope analyses revealed that the association of daily relationship commitment with support for the partner's goal pursuit was significant and positive when the relationship threat was lower than typical $(-1 S D), \beta=.07, t=1.96, p=.05$, but it trended nonsignificantly in the opposite direction when relationship threat was higher than typical $(+1 S D), \beta=-.03, t=-.83, p=.41$. In addition, when individuals had stronger relationship commitment than typical $(+1 S D)$, they exhibited weaker support for the partner when relationship threat was high versus low, $\beta=-.18, t=-4.13, p<$ .001. When individuals had weaker relationship commitment than typical (-1 SD), they showed the same tendency but to a lesser extent, $\beta=-.08, t=-1.88, p=.06$. These results were consistent with our findings in Studies 2a and 2b.

Next, we unpacked the commitment $\times$ personal threat interaction effect. As depicted in Figure 7, simple-slope analyses revealed that the association of daily relationship commitment with support for the partner was nonsignificant when the personal threat was lower than typical $(-1 S D), \beta=-.04, t=$ $-1.04, p=.30$, but it was significant and positive when personal threat was higher than typical $(+1 S D)$, $\beta=.08, t=2.35, p=.02$. In addition, when individuals had stronger relationship commitment than typical (+1 SD), they exhibited similar levels of support for the partner regardless of the levels of personal threat, $\beta=.04, t=.96, p=.34$. In contrast, when individuals had weaker relationship commitment than typical (-1 SD), they showed weaker support for the partner when personal threat was high versus low, $\beta=-.09, t=-2.12, p=.03$.

In sum, Study 3 demonstrated that the relationship threat and personal threat posed by the partner's daily goals moderate the within-person association between daily relationship commitment and support for the partner's goals. Consistent with Studies $2 \mathrm{a}$ and $2 \mathrm{~b}$, the results suggest that daily

relationship threat did not show the expected effect; indeed, if anything, it trended in the opposite direction. However, in light of the other findings of individual differences in relationship commitment presented in this paper, this opposite effect might be spurious. 
relationship threat moderates the association of daily relationship commitment with daily support for the partner's goals. Specifically, when the daily goals pose a relatively weak relationship threat, individuals are more supportive of their partner's goal pursuit on days when they endorse relatively high versus low relationship commitment. In contrast, when the daily goals pose a relatively strong relationship threat, individuals are equally unsupportive regardless of their daily levels of relationship commitment. These findings strongly support for the Manhattan effect predictions.

The results also suggest that daily personal threat moderates the association of daily relationship commitment with daily support for the partner's goals. Specifically, when the daily goals pose a relatively weak personal threat, participants are equally supportive of their partner's goal pursuit regardless of their daily levels of relationship commitment. In contrast, when the daily goals pose a relatively strong personal threat, participants become less supportive on days when they endorse relatively low versus high relationship commitment.

\section{Study 4: Support for the Partner's Personal Interests under High versus Low Threat of Relationship Dissolution}

In Studies 2a, 2b, and 3, we either manipulated or assessed the degree of conflict between the partner's interests (a hobby in these cases) and the relationship's interests, which allowed for direct tests of whether this conflict can reduce the positive association of commitment with intentions to engage in pro-partner behaviors. In the remaining studies, we focused on existential threats to a relationship — the very likely or certain dissolution of the relationship. In line with previous findings, we predicted that relationship commitment would predict greater willingness to support the partner's hobby when relationship threat is mild, but that this effect would become weaker, perhaps even disappearing or reversing, as the relationship threat becomes more severe. We also included a measure of relationship satisfaction and predicted that the commitment $\times$ threat interaction would remain robust even after controlling for the satisfaction $\times$ threat interaction. 


\section{Method}

Participants. Eighty-one mTurk volunteers in the United States (38 females, $M_{\text {Age }}=32.78, S D$ $=10.81)$ participated in the study. All were in an exclusive relationship. Forty-four participants were married, and the average relationship length was 7.67 years $(S D=8.87)$.

Procedures. Participants were randomly assigned to one of two versions of decision making task that differed in terms of the level of relationship threat. The decision making task was adapted from previous studies on willingness to sacrifice in one's relationship (Van Lange, Rusbult, et al., 1997). In our version, participants focused on the partner's important activities rather than their own important activities. Specifically, participants were asked to list three most important personal activities for their partner, other than their current relationship. Sample responses for these personal activities were "studying", "work", and "exercising".

Participants in the low threat condition then read:

Now, imagine that if your partner continued to engage in each of the below activities, it would create some conflicts to the relationship's interests. However, these conflicts related to this pursuit of your partner would put your relationship at very low risk of breaking up. To what extent would you encourage your partner to engage in each of the following activities, if conflicts related to this pursuit of your partner would put your relationship at very low risk of breaking up?

On the other hand, participants in the high threat condition then read:

Now, imagine that if your partner continued to engage in each of the below activities, it would create some conflicts to the relationship's interests. These conflicts related to this pursuit of your partner would almost certainly cause your relationship to break up, no matter how much you try hard to keep the relationship in good shape. To what extent would your encourage your 
partner to engage in each of the following activities, if conflicts related to this pursuit of your partner would almost certainly put your relationship to the end?

Participants then indicated on 7-point scales the degree to which they would encourage the partner to pursue each of the three activities $(1=$ definitely would not encourage him/her to engage in the activity to $7=$ definitely would encourage him/her to engage in the activity; $\alpha=.72$ ). Higher scores indicated greater intentions to support the partner's pursuit of important personal activities.

Relationship commitment and satisfaction. Participants finally filled out a 12-item relationship commitment scale ( $\alpha=.88$; Arriaga \& Agnew, 2001) and a 5-item relationship satisfaction scale $(\alpha=$ .92; Rusbult et al., 1998).

\section{Results and Discussion}

Hypothesis testing. We conducted a hierarchical regression analysis on intentions to support the partner's goals, with standardized commitment and satisfaction scores and contrast-coded variable of threat condition $(-1=$ low threat and $1=$ high threat $)$ entered into the first step and the commitment $\times$ threat and satisfaction $\times$ threat interaction into the second step. Consistent with our hypotheses, the results presented in Table 6 revealed that the commitment $\times$ threat interaction effect was significant and that the satisfaction $\times$ threat interaction was not.

As depicted in Figure 8, simple-slope analyses revealed that the association of relationship commitment with intentions to support the partner was significant and positive in the low threat condition, $\beta=.30, t(75)=2.06, p=.04$, but it trended nonsignificantly in the opposite direction in the high threat condition, $\beta=-.24, t(75)=-1.16, p=.25$. In addition, highly committed individuals $(+1 S D)$ exhibited weaker intentions to support the partner in the high versus the low threat condition, $\beta=-.76$, $t(75)=-4.78, p<.001$, but this association was nonsignificant among less committed individuals $(-1$ $S D), \beta=-.22, t(75)=-1.39, p=.17$. 
Thus, these findings showed that strong existential threat posed by the partner's interests, threat that is likely but not totally certain to end the relationship, moderates the association of relationship commitment with pro-partner inclinations. When the partner's interests only pose low threat to the relationship, highly committed individuals have stronger intentions to support their partner than do less committed individuals. In contrast, when the partner's interests pose a potentially existential threat to the relationship, highly committed individuals do not have stronger intentions to support their partner, and, if anything, they have (nonsignificantly) weaker intentions to do so.

\section{Study 5a: Support for the Partner's Personal Interests under Extreme Existential Relationship Threat}

In Studies 5 and 6, we investigated situations where the existential threat is certain, rather than probable, and tested how far highly committed individuals are willing to go to protect the relationship. Specifically, we examined the association between relationship commitment and support for the partner's interests in an extreme case where these the pursuit of interests will definitively end the relationship. Will relationship commitment cause people to undermine a partner's personal interests when those interests present a certain existential threat to the relationship? Would highly committed individuals be even more unsupportive than less committed individuals in these contexts?

In Study 5a, participants reported the degree to which they would promote their partner's pursuit of a goal that poses a severe relationship threat that will result in relationship dissolution. We predicted that highly versus less committed individuals would not only fail to be especially supportive of their partner's interests, but would actually undermine their partner's interests. Therefore, we predicted a negative association between relationship commitment and support for the partner in this context.

\section{Method}


Participants and procedures. One hundred and forty-four mTurk volunteers in the United States ( 76 females, $M_{\text {Age }}=30.17, S D=10.56$ ) participated in the study. All were in an exclusive relationship. Sixty-five participants were married, and the average relationship length was 9.14 years $(S D=28.54)$.

Measures. Participants were asked to complete the following measures that were presented in a randomized order.

Relationship commitment. Participants filled out a 12-item relationship commitment scale (Arriaga \& Agnew, 2001; $\alpha=.88$ ).

Decision-making task. We revised the decision making task in Study 4 to make the existential threat more severe by describing it as a certain one. Specifically, participants were asked to list three most important personal activities for their partner, other than their current relationship. Participants were then asked to imagine that it was impossible for their partner to pursue the three activities listed without ending the relationship. Participants then indicated on 7-point scales the degree to which they would encourage the partner to pursue each of the three activities $(1=$ definitely would not encourage him/her to engage in the activity to $7=$ definitely would encourage him/her to engage in the activity; $\alpha$ $=.66$ ). Higher scores indicated greater intentions to support the partner's pursuit of important personal activities.

\section{Results and Discussion}

In general, when the partner's goals posed an existential relationship threat, relationship commitment tended to reduce support for these goals $(r=-.38, p<.001)$. Study 4 had demonstrated that highly committed individuals tend to be as unsupportive as less committed individuals when the partner's pursuit of his or her personal interests is extremely likely to end the relationship. Study 5a 
further demonstrated that highly committed individuals could be even more unsupportive than less committed individuals when the existential threat is certain to end the relationship. ${ }^{6}$

\section{Study 5b: The Causal Role of Relationship Commitment under Extreme Existential Relationship Threat}

Study $5 \mathrm{~b}$ sought to establish the causal effects of relationship commitment on support for the partner by directly manipulating it. This study used the same scenario described in Study 5a to measure participants' willingness to support their partner's personal interests even when these interests posed a certain, existential relationship threat. Again, we predicted that, when the partner's interests in this case pose a certain, existential threat to the relationship, highly versus less committed individuals would want to undermine their partner's interests. Therefore, we predicted a negative effect of (primed) relationship commitment on support for the partner in this context.

In this study, we further explored whether the participants' perception of the partner's preferences for his or her own interests over the relationship's interests would intensify the negative association between relationship commitment and support for the partner. If such an effect was to emerge, the Manhattan effect could plausibly reflect retaliatory or self-protective intentions against the partner's potential exploitation of their support. If not, it would suggest that, as we hypothesized, the participants' perception of the partner's unwillingness to sacrifice for the relationship is not a necessary condition for the Manhattan effect to occur; the situational misalignment of the partner's and the relationship's interests is sufficient.

\section{Method}

\footnotetext{
${ }^{6}$ We also assessed social value orientation (Van Lange, Agnew, et al., 1997; Van Lange, Otten, De Bruin, \& Joireman, 1997), communal orientation (Clark, Oullette, Powell, \& Milberg, 1987), and unmitigated communion (Helgeson \& Fritz, 1998). These prosocial dispositions neither correlated with the dependent measure nor moderated the effects of commitment, suggesting that they might not be relevant to pro-partner behaviors that have relationship costs.
} 
Participants. Seventy-six mTurk volunteers in the United States (42 females, $M_{\text {Age }}=32.21$, $S D=9.72)$ participated in the study. All were in an exclusive relationship. Thirty-eight participants were married, and the average relationship length was 7.58 years $(S D=8.31)$.

Procedures. In this study, we manipulated relationship commitment before making decisions. As in Study 4a, participants were first asked to list three most important personal activities for their partner, other than their current relationship.

Adapting procedures from previous research (Finkel et al., 2002), participants in the high commitment prime condition answered three questions designed to activate thoughts regarding dependence and commitment. The three questions were: "List two reasons why you may want to be committed to your relationship for the long-run", "List two activities that you enjoy engaging in with your partner", and "List two reasons why it would be nice to stay with your partner for your whole life." Participants in the low commitment prime condition answered three questions regarding independence and lack of commitment. The three questions were: "List two reasons why you may not want to be committed to your relationship for the long-run", "List two activities that you enjoy engaging in without your partner", and "List two ways in which it would be nice to remain single for your whole life."

As in Study 5a, participants were then asked to imagine that it was impossible for their partner to maintain the three activities listed without ending the relationship. Participants then directly indicated on 7-point scales the degree to which they would encourage the partner to pursue each of the three activities $(1=$ definitely would not encourage him/her to give up the activity to $7=$ definitely would encourage him/her to give up the activity; $\alpha=.40)$. These items were reverse-scored so that high scores reflected stronger intentions to support the partner's goal.

Participants also indicated on 7-point scales their perception of the partner's preferences $(1=$ definitely he/she would not prefer to give up the activity to $7=$ definitely he/she would prefer to give up 
the activity; $\alpha=.52$ ). These items were reverse-scored so that high scores reflected stronger preference for personal goals over the relationship. The presentation order of the two sets of questions regarding support for partner's goals and perceived partner's preference was randomly determined. Participants finally filled out a 12-item relationship commitment scale $(\alpha=.86$; Arriaga \& Agnew, 2001) and a 5item relationship satisfaction scale $(\alpha=.89$; Rusbult et al., 1998).

\section{Results and Discussion}

Manipulation check. The analysis of the manipulation check showed that participants in the high commitment prime condition $(M=4.62, S D=.34)$ reported a higher level of relationship commitment than participants in the low commitment prime condition $(M=4.26, S D=.62), t(74)=$ $3.11, p<.01$. In addition, the manipulation did not induce differences in relationship satisfaction $(M=$ 4.13, $S D=.74$ vs. $M=4.02, S D=.73, t(74)=.63, p=.53)$ and in perceived partner's preference $(M=$ $4.31, S D=1.79$ vs. $M=4.39, S D=1.35, t(74)=-.24, p=.81)$. In short, relationship commitment manipulation was successful.

Hypothesis testing. We conducted a hierarchical regression analysis on intentions to support the partner's goal, with contrast-coded variable of experimental conditions $(-1=$ low commitment and 1 = high commitment ) and standardized scores of perceived partner's preference entered into the first step and their interaction into the second step. Consistent with Study 4a, we observed the main effects of commitment, such that participants in the high $(M=4.89, S D=1.42)$ versus less $(M=5.47, S D=$ 1.15) commitment prime condition reported less support for partner's goals when the goals posed threat to the relationship, $\beta=-.23, t(73)=-2.01, p=.05$. Moreover, as predicted, perceived partner's preference did not moderate this effect of relationship commitment, $\beta=.11, t(71)=.98, p=.33$.

Overall, these results, in conjunction with those from previous studies, suggest that highly versus less committed individuals are willing to compromise their own and their partner's personal interests in order to protect the relationship from dissolution. These findings beg an important follow- 
up question: Under what circumstances, if any, would highly committed individuals no longer prioritize the maintenance of their relationship over their partner's interests (and their own)?

\section{Study 6: The Pro-relationship Nature of Relationship Commitment}

Study 6 delved deeper into the circumstances under which committed people might be willing to undermine their partner's personal interests when that pursuit will unambiguously and directly result in relationship dissolution. Previous research has demonstrated that, under such extreme circumstances, highly committed individuals are especially willing to protect their relationship by undermining their own personal interests outside the relationship (e.g., Van Lange, Rusbult, et al., 1997; Wieselquist et al., 1999), and Studies 2-5 in the present article have demonstrated that highly committed individuals are especially willing to protect their relationship by failing to prioritize or undermining their partner's personal interests outside the relationship. Study 6 examined whether highly committed individuals remain especially willing to protect their relationship when doing so requires that they undermine both their own and their partner's personal interests. In other words, this study examined whether relationship threat causes highly committed people to prioritize the relationship even at the expense of both partner's personal interests.

The key manipulation was the type of joint personal interests (or goals of both parties) considered: relationship-independent and relationship-dependent goals. Specifically, we compared joint personal interests outside the relationship (i.e., goals that were not dependent upon the relationship) and joint personal interests inside the relationship (i.e., goals that were dependent on the relationship). At its essence, relationship commitment represents the concerns for maintaining the interdependence structure or the established pattern of reciprocal cooperation that supports both partners' relationship-dependent personal interests (Axelrod, 1984; Rusbult et al., 2004). Consistent with this notion, and with the results from Study 3, highly committed individuals are more willing to sacrifice own self-interests to support their partner's goal pursuit outside the relationship, because such 
behaviors are frequently necessary to maintain and strengthen the relationship that can, despite immediate personal costs, protect and bolster both parties' core relationship-dependent interests in the long run. However, if the relationship can no longer sustain the relationship-dependent interests or the core intrinsic bases of interdependence, relationship commitment based on these intrinsic values of the relationship may no longer fuel intentions to maintain this dysfunctional relationship. Therefore, threats to the relationship-dependent interests may be the boundary condition under which relationship commitment no longer increases intentions to protect the relationship.

Accordingly, we predicted that relationship commitment would reduce willingness to support to both parties' relationship-independent goals when these interests are not compatible with relationship maintenance. However, we also predicted that relationship commitment would not reduce willingness to preserve both parties' relationship-dependent goals (e.g., intimacy and sexual activities) when these interests are no longer supported by the relationship. In Study 6, we again manipulated relationship commitment to allow for causal conclusions.

\section{Method}

Participants. Eighty-two mTurk volunteers in the United States (49 females, $M_{\text {Age }}=33.38, S D$ =9.79) participated in the study. All were in an exclusive relationship. Forty-three participants were married, and the average relationship length was 6.88 years $(S D=6.63)$.

Procedures. All participants were first randomly assigned to one of two commitment conditions as in Study 5b. Participants were then randomly assigned to make choices regarding to their joint interests outside or inside the relationship.

\section{Measures.}

Choice between the relationship and goals of both parties. In the relationship-independent goals condition, we asked participants to list the three most important activities that were independent of their relationship — separately for themselves and for their partner. Sample responses for these 
personal activities were "work", "reading the Bible", and "watching movies". In the relationshipdependent goals condition, we asked participants to list the three most important activities that were dependent on the relationship — separately for themselves and for their partner. Sample responses for these personal activities were "having sex", "dates", and "spending time together").

To pit relationship well-being against joint personal well-being, we asked participants to make three forced choices regarding each of the three pairs of important activities for the participants and their partner.

In the relationship-independent goals condition, participants then read:

Imagine that for some reasons, your relationship with your partner becomes incompatible with your engagement in $<$ own independent activity $1>$ and your partner's engagement in $<$ partner's independent activity $1>$. To what extent would you want to keep the relationship when both of you experience conflicts between the relationship and these activities?

In the relationship-dependent goals condition, participants then read:

Imagine that for some reasons, your relationship with your partner can no longer support your engagement in $<$ own dependent activity $1>$ and your partner's engagement in $<$ partner's dependent activity $1>$. To what extent would you want to keep the relationship when both of you can no longer receive from the relationship the support for these activities?

Participants answered on 7-point scales $(1=$ definitely no to $7=$ definitely yes; $\alpha=.87)$. The items were reverse-coded so that higher scores represented stronger intentions to protect joint interests at expense of the relationship. 
Manipulation check. Finally, to make sure that the manipulation was successful, participants filled out a 12-item relationship commitment scale $(\alpha=.85$; Arriaga \& Agnew, 2001) and a 5-item relationship satisfaction scale ( $\alpha=.88$; Rusbult et al., 1998).

\section{Results and Discussion}

We performed 2 (Commitment: Low vs. High) $\times 2$ (Types of Goals: Relationship-Independent vs. Relationship-Dependent Goals) ANOVAs for subsequent analyses.

Manipulation check. The ANOVA was first conducted on the manipulation check. Participants in the high commitment prime condition $(M=4.68, S D=.43)$ reported a higher level of relationship commitment than participants in the low commitment prime condition $(M=4.43, S D=.52), F(1,78)$ $=5.70, p=.02$. Moreover, the commitment manipulation appeared to be equally effective across manipulations of type of goals, $F(1,78)=.03, p=.87$. Critically, as in Study $5 \mathrm{~b}$, the commitment manipulation did not affect relationship satisfaction, $M=4.31, S D=.69$ vs. $M=4.14, S D=.62, F(1$, 78) $=1.31, p=.26$.

Hypothesis testing. The ANOVA on the primary dependent variable-intentions to support goals for both parties (vs. to maintain the relationship)—revealed a null main effect of commitment, $F(1,78)=1.24, p=.27$. The ANOVA also revealed a significant main effect of type of goals, $F(1,78)$ $=15.16, p<.001$, such that individuals were less inclined to protect relationship-independent $(M=$ 2.23, $S D=1.17)$ versus relationship-dependent goals $(M=3.53, S D=1.73)$. Critically, the ANOVA also revealed the predicted two way-interaction between relationship commitment and type of goals was significant, $F(1,78)=4.48, p=.04$.

As depicted in Figure 9, tests of simple effects revealed that participants in the high $(M=1.79$, $S D=.93)$ versus low $(M=2.81, S D=1.21)$ commitment prime condition showed weaker intentions to protect relationship-independent goals when these goals were incompatible with the relationship, $F(1$, $78)=5.57, p=.02$. Thus, relationship commitment leads individuals to value the continuation of the 
relationship over the combined value of their partner's and their own extra-relationship interests. In contrast, participants in the high $(M=3.68, S D=1.73)$ and low $(M=3.37, S D=1.76)$ commitment prime conditions did not differ in their intentions to protect relationship-dependent goals when these goals were no longer supported by the relationship, $F(1,78)=0.47, p=.50$; indeed, if anything, the pattern of means trended in the opposite direction from those found in the relationship-independent goals condition. In addition, highly committed individuals exhibited weaker intentions to protect relationship-independent versus relationship-dependent goals, $F(1,78)=19.28, p<.001$. However, less committed individuals' exhibited similar levels of intentions to protect the relationshipindependent and -dependent goals, $F(1,78)=1.49, p=.27$.

In sum, the results suggest that highly committed individuals are willing to take steps to undermine their own and their partner's relationship-independent personal interests to protect the relationship. However, they appear to be every bit as likely to disengage from the relationship as less committed individuals are, when the foundational essence of their interdependence (i.e., their own and their partner's relationship-dependent personal interests) is unfulfilled within the relationship.

\section{General Discussion}

This research distinguished the partner's and the relationship's interests and examined how relationship commitment relates to behaviors oriented toward these two different interests when they are disentangled from each other. In Studies 1a and 1b, we found that, although people's concerns oriented toward for partner's interests and for the relationship's interests tended to be highly (albeit not perfectly) correlated, relationship commitment was only positively associated with actual effort when the pursuit was intended for the relationship's interests, not for the partner's interests.

In a series of direct tests of our Manhattan effect hypothesis, we examined interpersonal situations in which the partner's and the relationship's interests are in conflict, and found strong and consistent support for the hypothesis that relationship threat associated with a partner's personal 
interests reduces, and sometimes even reverses, the typically positive association of relationship commitment with pro-partner behaviors. In Studies 2a, 2b, and 3, relationship commitment predicted greater willingness to support the partner's personal interests in the absence of relationship threat. However, in the presence of relationship threat, relationship commitment did not predict willingness to support the partner's personal interests. In Studies 4-6, we investigated extreme cases in which the partner's goal pursuit yielded an existential threat to the relationship. We found that relationship commitment did not predict willingness to support the partner's personal interests in the presence of a highly likely existential threat (Study 4) and predicted a tendency to undermine that pursuit in a certain existential threat (Studies 5-6). This undermining effect emerged whether the goal pursuit involved only the partner's interests (Studies 5a and 5b) or also the joint interests of both parties outside the relationship (the relationship-independent goals condition in Study 6). Crucially, however, it disappeared when the goal pursuit undermined the most essential basis of interdependence (i.e., the core joint interests that both parties depend on the relationship; the relationship-dependent goals condition in Study 6).

Attesting to the robustness of the phenomenon, these results emerged both when relationship commitment was measured with self-reports (Studies 1a, 1b, 2a, 2b, 3, 4, and 5a) or directly manipulated (Studies 5b and 6). They also emerged across diverse operationalizations of the partner's personal interests, including the partner's important personal activities in their life (Studies 1a, 4, 5a, 5b, and 6), daily personal goals (Studies $1 \mathrm{~b}$ and 3), specific personal hobbies (Study 2a), and general long-term interests (2b) - and in the context of hypothetical scenarios, in real-life interests from the recent past, and in daily-diary and experience-sampling reports.

\section{Interdependence Analysis of Relationship Commitment and Pro-partner Behaviors}

This research clarifies the surprisingly precarious nature of the positive link between relationship commitment and support for one's partner's interests. According to interdependence 
theory (Kelley \& Thibaut, 1978), people have gut-level impulses to pursue self-interests even at other's personal costs. Relationship commitment inspires broader considerations for the partner and the relationship by the means of transformation of motivation (e.g., Agnew, Van Lange, Rusbult, \& Langston, 1998; Finkel \& Rusbult, 2008). Highly committed individuals are supposed to be especially willing to endure personal costs to benefit the partner and the relationship. Our analysis challenged this analysis by underscoring the importance of distinguishing between partner-oriented and relationshiporiented motivations for support.

Conflating the two, as in all relevant prior research, paints a picture of highly committed individuals as benevolent and partner-oriented. By considering circumstances under which the partner's personal interests may potentially undermine the well-being of relationship, these findings allowed us to examine the different preferences produced by partner-oriented and relationship-oriented transformations, and offered important insights into how relationship commitment causes people to prioritize relationship well-being over partner well-being when the two are in conflict. Consistent with existing theorizing (Rusbult \& Buunk, 1993; Rusbult et al., 2001), our studies showed that more versus less committed individuals are more supportive of their partner's personal interests, especially when such support could undermine their own personal interests (Study 3). Central to our theoretical analysis, we found that when relationship well-being is not threatened by the partner's interests (Studies 2-4), highly versus less committed individuals support their partner's personal interests, perhaps because such support has the potential to benefit the relationship in a long run (cf. Murray et al., 2009). In contrast, when relationship well-being is threatened by the partner's interests, highly versus less committed individuals neglect, and sometimes even undermine, their partner's interests. Taken together, the results suggest that less committed individuals tend to be unwilling to endure personal threats to support their partner's interests, whereas highly committed individuals tend to be unwilling to endure relationship threats to support their partner's interests. 
These findings cast doubt on the extent to which relationship commitment evokes purely unconditional other-oriented concerns for the partner's welfare, as suggested in the previous interdependence analyses (Finkel et al., 2002; Rusbult et al., 2001). Indeed, previous studies have primarily examined interpersonal situations where the partner's interests align with the relationship's interests, such that pro-partner behavior can be used strategically to promote the well-being of the relationship well-being (Rusbult et al., 2004). The present research suggests that relationship commitment may promote pro-partner behaviors in these situations exclusively through elevated relationship-oriented concerns, even in the absence of any elevated partner-oriented concerns. Indeed, our studies showed that (a) highly versus less committed individuals did not put more efforts into goals that were uniquely more versus less relevant to the partner's interests beyond the relevance of the goals to the relationship's interests (Study 1); and (b) when the partner's interests conflicted with the relationship's interests, highly committed individuals consistently protected the relationship (the Manhattan effect; Studies 2-6). These findings altogether suggest that, for these highly committed individuals, the relationship's well-being trumps the partner's. In short, it appears that the partneroriented concerns inspired by relationship commitment might not be as powerful as previously believed (Rusbult et al., 2004), and can be dominated by other commitment-inspired concerns. Future studies should further clarify (whether and) when relationship commitment might evoke pro-partner behaviors in situations where the relationship's interests are not at stake (e.g., anonymously supporting the partner's personal goals in the absence of opportunities to claim credits from the partner).

Although it was plausible a priori that the Manhattan effect was driven by individuals' perception that the partner's interest in pursuing the relationship-threatening activity signified a lack of commitment to the relationship, we believe that it is not a necessary condition for the Manhattan effect to occur. Supporting this notion, Study 2 a showed that, even when the partner did not show any lack of commitment and yet his or her interest posed a threat to the relationship (i.e., the partner was only 
admitted in one distant school and did respect the participants by asking for advice), highly committed individuals would become as unsupportive as less committed individuals. Also, Study $5 b$ showed that highly committed individuals were more willing to undermine their partner's interests for the relationship, regardless of their perception of their partner's preferences or willingness to sacrifice. Still, future studies might explore the indirect roles of perceived partner's commitment inferred from the past interaction history (versus the partner's specific personal interests) on the Manhattan effect (e.g., its influence on subjective appraisals of relationship threat).

Are there circumstances under which highly committed people become no more willing than less committed people to maintain the relationship? This research and other findings demonstrate that more versus less committed individuals are more willing to protect the relationship's interests even if doing so undermines either their own (Powell \& Van Vugt, 2003; Van Lange, Rusbult, et al., 1997) or their partner's (Studies 2-5) personal interests outside the relationship—or even both (Study 6). Study 6 also highlighted a crucial boundary condition in which highly committed individuals are no more willing to maintain the relationship than less committed individuals: when the relationship-dependent personal interests are no longer supported, which signals fundamental dysfunction in the relationship. In short, it seems that relationship commitment generally inspires people to sacrifice their own and their partner's interests for the sake of the relationship, but this effect disappears when the relationship's foundation is rotten. This finding serves as a caveat to the perspective that relationship commitment functions as "commitment to lines of action that will prevent the elimination of interdependence" (M. P. Johnson, 1991, p. 120) by suggesting that even highly committed individuals are willing to eschew such lines of action when nothing can be done to preserve the loss of the core value of the relationship.

Thus far, our studies have consistently shown that highly committed individuals are more likely to reduce support for their partner's interests to the extent that these interests threaten the relationship's 
interests. Relationship's interests are not just about relationship stability but also about the maintenance of a functioning interdependence that supports needs of both parties. Indeed, as discussed previously, even highly committed individuals would not desire to keep an empty relationship that does not fulfill relationship-dependent needs (Study 6). Therefore, promoting relationship commitment might not be panacea for relationship problems. To truly protect the relationship's interests, individuals need to make sure that the relationship not only is alive, but also that it serves to support needs of both parties. Consider, for example, what Isaac says to Tracy as he attempts to convince her not to study abroad in London. In expressing why he is so concerned about her leaving the country, he explains that he is concerned that she will change: "in six months you'll be a completely different person" and "I just don't want that thing about you that I like to change." To be sure, he is probably concerned that those changes will undermine his commitment or hers, but his central point is that the relationship is dependent upon each of them being just as they are today, and either person's change or maturity runs the risk of changing the essence of the relationship. He is not primarily concerned that she will fall out of love with him or fall in love with another man while she is in London, but rather that the essence of what makes their relationship so good will change.

Following the interdependence theory tradition (e.g., Rusbult et al., 2001), the present research has focused on relationship commitment that is based upon personal attraction to and intrinsic values of the relationship. However, relationship commitment can also develop on the bases of structural constraints and moral values (Adams \& Jones, 1997; M. P. Johnson, 1991). Relationship commitment based upon these different bases may influence pro-partner behaviors in ways that are very different from relationship commitment based upon the intrinsic value of the relationship. For instance, individuals who stay in a relationship for structural or controlled reasons (e.g., financial dependence) tend to engage in more defensive behaviors in relationship conflicts that hurt both relationship wellbeing and partner's well-being (Knee, Hadden, Porter, \& Rodriguez, in press; Knee, Lonsbary, 
Canevello, \& Patrick, 2005). Also, individuals who stay in a relationship out of their moral values might have moral concerns for the partner's well-being (Rai \& Fiske, 2011). If relationship commitment is derived from this moral basis, it may promote rather than prohibit pro-partner behaviors even if these behaviors would be against the relationship's interests. Future research could fruitfully examine how distinct underlying bases of relationship commitment might differentially affect pro-partner behaviors when the partner's interests pose a threat to the relationship.

\section{Conflicts between the Partner's Interests and the Relationship's Interests: A Novel Direction for}

\section{Interdependence Research}

Previous research has examined a broad range of situations in which the partner's and relationship's interests align with each other. Under these circumstances, partner-oriented and relationship-oriented transformations of motivation both yield unselfish, benevolent interpersonal behaviors (e.g., Balliet, Li, \& Joireman, 2011; Van Lange, Agnew, et al., 1997; Van Lange, Klapwijk, \& Van Munster, 2011). In contrast, as noted in the Introduction, interdependence analyses of relationship maintenance mechanisms have largely neglected interpersonal situations where the partner's and the relationship's interests do not align. Our pilot study (see Footnote 3) demonstrated that people frequently experience such misalignment, just as Isaac did at the end of Manhattan.

To our knowledge, although interpersonal conflict between the partner's and the relationship's well-being had not been formally introduced or systematically analyzed in the close relationships literature before the present analysis, many interpersonal behaviors researched in the literature may actually involve the navigation and negotiation of such misalignment. For instance, enthusiastically responding to the partner's good news about an internship abroad may promote the partner's wellbeing, but it also means accepting the loss of time spent together (Gable \& Reis, 2010). Similarly, nagging and pushing a partner with poor self-control to refrain from overeating may benefit the partner's health goal but sour the relationship (Overall, Fletcher, Simpson, \& Sibley, 2009). On the 
other hand, regulating a partner to meet one's relationship standard may undermine the partner's selfevaluation but improve relationship quality (Overall, Fletcher, \& Simpson, 2006). Also, demanding a partner to bear more family responsibilities may undermine the partner's career aspiration but sustain relationship coordination (Amstad, Meier, Fasel, Elfering, \& Semmer, 2011).

An analysis of conflict between the partner's and the relationship's well-being may also apply to extreme, pathological behaviors in close relationship. For instance, jealousy evoked by a potential romantic rival may motivate controlling and even abusive behaviors against the partner's well-being to protect the relationship (e.g., Dutton, van Ginkel, \& Landolt, 1996; Sackett \& Saunders, 1999). In problematic relationships, people sometimes engage in "intimate terrorism” (M. P. Johnson, 2008), a severe and controlling form of intimate partner violence that hurts the partner's physical and psychological well-being but can serve to deter the partner from leaving the relationship, especially if the intimate terrorism involves credible threats to the partner's well-being in the event of relationship dissolution (Buss \& Shackelford, 1997). The current interdependence analysis of such conflicts allows for an integrative synthesis of these diverse relationship processes by emphasizing their situational configurations.

Finally, people's behavioral intentions in the conflicts between the partner's and the relationship's interests can reveal their predominantly partner-oriented or relationship-oriented concerns. We have shown that relationship commitment contributes to predominantly relationshiporiented concerns. Still, it is important to identify and explain which broader relationship norms, dispositions, and relational factors predispose individuals to engage in partner-oriented transformation of motivations and to protect the partner's interests even at the costs of the relationship, such as when parents are willing to let their children grow apart from them in order to develop into independent adults (Kelley et al., 2003; Kelley \& Thibaut, 1978).

\section{Limitations and Strengths}


The present studies possess limitations and strengths. One limitation is that, for practical and ethical reasons, we had to resort to scenario measures to capture extreme relationship threats that would directly lead to relationship dissolution. A second limitation is that our studies exclusively relied on self-reports of pro-partner intentions. Although self-reports of such dynamics represent standard assessment procedures (e.g., Molden \& Finkel, 2010; Van Lange, Agnew, et al., 1997), and arguably optimal ones for assessing participants' internal motivational state, this line of research would benefit from future studies employing behavioral observations in standardized lab settings.

Switching from limitations to strengths, one strength is that we examined the conflicts between the partner and the relationship by incorporating multiple methods, including reports on real-life events (Studies 1, 2b and 3) and reports on standardized scenarios that strictly controlled the level of relationship threat (Studies 2a, 4, 5, and 6). The reports of real-life events afforded ecological validity, whereas the other tasks afforded internal validity by employing tight experimental control. A second strength is our use of diverse methods of examining relationship commitment. In addition to one-shot measurements (Studies 1, 2, 4, and 5a) and multiple daily assessments (Study 3), relationship commitment was also manipulated using brief essays (Studies $5 \mathrm{~b}$ and 6). These results allowed us to establish the causal role of relationship commitment. A third strength is that our participant samples were diverse in terms of age and marital status. A fourth strength is that our results provided clear and consistent support for our theoretical analysis despite the diversity of methodologies and participant samples.

\section{Additional Directions for Future Research}

We suggest three additional directions for future research, all of which focus on the dyadic implications of conflict between the partner's and the relationship's interests. First, given that highly committed individuals undermine their partner's interests out of relationship-oriented concerns in the partner-versus-relationship conflict (Studies 2-6), future research could examine how their partner 
responds to these behaviors. Concerns for the partner's welfare are normatively expected in close relationships (Clark, Lemay, Graham, Pataki, \& Finkel, 2010), and they are codified in terms of communal norms (Clark \& Mills, 1979, 1993). Sacrificing the partner's well-being for self-interested reasons is considered socially inappropriate and counter-normative. However, is it less inappropriate and more forgivable when these anti-partner behaviors are motivated by pro-relationship reasons? We believe so. Indeed, it is plausible that individuals uphold the communal norm of caring for the partner's welfare largely because they value the relationship (Clark \& Mills, 1993; Kelley et al., 2003). Perpetrators who undermine the partner's interests to avoid immediate threats to the relationship are more likely to engage in reparative behaviors (e.g., amends-making) afterward to compensate for the loss of intimacy and dependence. As long as the perpetrator does not seek to repeatedly exploit the victim and makes sincere amends, the victim may be more forgiving (Burnette, McCullough, Van Tongeren, \& Davis, 2012; Hannon, Rusbult, Finkel, \& Kamashiro, 2010) and have better adjustment after forgiving (Luchies, Finkel, McNulty, \& Kumashiro, 2010; Pansera \& La Guardia, 2012).

Second, future research could examine the ways in which frequent relationship threat may disrupt pro-partner behaviors and dyadic interdependence processes over time, which may thereby undermine both partners' personal growth. People heavily rely on their partners to support their goals and personal growth (Finkel, Hui, Carswell, \& Larson, in press; Fitzsimons \& Finkel, 2010; Reis et al., 2000; Rusbult et al., 2009). Not supporting the partner's goals may therefore undermine relationship well-being in the future. As shown in our studies, commitment-inspired pro-partner behaviors are largely reduced by potential threats to the relationship posed by the partner's interests. When such threats are prevalent and frequently disrupt precisely those pro-partner behaviors that signal one's responsiveness to the partner (Murray \& Holmes, 2009; Wieselquist et al., 1999), they may ultimately undermine the partner's trust and dependence. This problem can be exacerbated when individuals inaccurately identify potential relationship threat in a given situation due to their biased or incomplete 
understanding of the partner's situations, preferences, and histories (cf. Van Lange, Ouwerkerk, \& Tazelaar, 2002). In ambiguous situations, relationship threats can be largely subjective and dependent upon sensitivity of the threat monitoring system, as indexed by rejection sensitivity (Downey, Freitas, Michaelis, \& Khouri, 1998), attachment anxiety (Campbell, Simpson, Boldry, \& Kashy, 2005), and low self-esteem (Murray \& Holmes, 2008). A hypersensitive person may frequently be discouraged from supporting the partner's personal interests by falsely perceiving relationship threats. Future research could fruitfully examine how frequent occurrences of relationship threats, as well as these threat sensitivities, disrupt normative pro-partner behaviors and how these processes may ironically contribute to maladaptive interdependent processes that undermine the partner's personal growth despite the presence of strong relationship-oriented motivations.

Finally, future research could examine which type of motivations people prefer their partner to adopt and the individual differences and situational circumstances that might moderate this preference. Given that people are attracted to other people by the rewards and benefits those others provide (Berscheid \& Hatfield, 1969; Finkel \& Eastwick, in press), they may have different preferences for relationship-oriented or partner-oriented partners because of the different benefits (and costs) these different types of partners offer (e.g., Fitzsimons \& Fishbach, 2010; Hui, Molden, \& Finkel, 2013). As illustrated in the Manhattan effect, relationship-oriented individuals may not always be generous to their partner and may impose constraints of freedom, but these gestures can be desired as reassurance that they are committed to maintaining the relationship even when confronting obstacles. In contrast, although partner-oriented individuals may support their partner's personal interests across circumstances without expectations of reciprocation, their partner may feel guilty if he or she fails to reciprocate (e.g., Buunk \& Schaufeli, 1999; Gleason, Iida, Bolger, \& Shrout, 2003; Uehara, 1995). In addition, because relationship protection is so strongly tied to relationship commitment, individuals may see partner-orientation over relationship-orientation as a cue that a partner simply isn't committed, 
as illustrated toward the beginning of Manhattan, when Isaac enthusiastically supports Tracy's studyabroad opportunity. Preferences for different types of partners may be determined by individual differences, including attachment styles (Fraley \& Shaver, 2008) and relative priorities between personal and relational concerns (Kumashiro et al., 2008). For instance, people who are anxiously attached or prioritize the relationship over personal concerns may prefer a relationship-oriented partner more, as they are more willing to have their personal growth opportunities quashed to preserve interdependence (e.g., Impett \& Gordon, 2010; Slotter \& Finkel, 2009; Slotter \& Gardner, 2011). Similarly, situational circumstances that motivate different attachment styles and priorities between personal and relational concerns would also be related to these preferences as well.

\section{Conclusions}

The present program of research examines the prosocial nature of relationship commitment. The evidence for the Manhattan effect demonstrates that, although highly versus less committed individuals are especially willing to support their partner's personal interests when the relationship is not threatened, they are also willing to neglect or even undermine those interests when the relationship is threatened. This research clarifies the motivational priorities of relationship commitment and highlights the importance of studying the conflict between the partner's interests and the relationship's interests, which has been largely neglected in the relationships research. 


\section{References}

Adams, J.M., \& Jones, W.H. (1997). The conceptualization of marital commitment: An integrative analysis. Journal of Personality and Social Psychology, 72, 1177-1196. doi: 10.1037/00223514.72.5.1177

Agnew, C.R., Van Lange, P.A.M., Rusbult, C.E., \& Langston, C.A. (1998). Cognitive interdependence: Commitment and the mental representation of close relationships. Journal of Personality and Social Psychology, 74, 939-954. doi: 10.1037/0022-3514.74.4.939

Aiken, L.S., \& West, S.G. (1991). Multiple regression: Testing and interpreting interactions. Thousand Oaks, CA, US: Sage.

Amstad, F.T., Meier, L.L., Fasel, U., Elfering, A., \& Semmer, N.K. (2011). A meta-analysis of workfamily conflict and various outcomes with a special emphasis on cross-domain versus matching-domain relations. Journal of Occupational Health Psychology, 16, 151-169. doi: $10.1037 / \mathrm{a} 0022170$

Arriaga, X.B., \& Agnew, C.R. (2001). Being committed: Affective, cognitive, and conative components of relationship commitment. Personality and Social Psychology Bulletin, 27, 1190-1203. doi: 10.1177/0146167201279011

Axelrod, R. (1984). The evolution of cooperation. New York: Basic Books.

Balliet, D., Li, N.P., \& Joireman, J. (2011). Relating trait self-control and forgiveness within prosocials and proselfs: Compensatory versus synergistic models. Journal of Personality and Social Psychology, 101, 1090-1105. doi: 10.1037/a0024967

Berscheid, E., \& Hatfield, E. (1969). Interpersonal attraction. London Addison-Wesley Publishing Company. 
Blais, M.R., Sabourin, S., Boucher, C., \& Vallerand, R.J. (1990). Toward a motivational model of couple happiness. Journal of Personality and Social Psychology, 59, 1021-1031. doi: $10.1037 / 0022-3514.59 .5 .1021$

Bolger, N., \& Laurenceau, J.-P. (2013). Intensive longitudinal methods. New York: Guilford.

Buhrmester, M.D., Kwang, T., \& Gosling, S.D. (2011). Amazon's mechanical turk: A new source of inexpensive, yet high-quality, data? Perspectives on Psychological Science, 6, 3-5. doi: $10.1177 / 1745691610393980$

Burnette, J.L., Davisson, E.K., Finkel, E.J., Van Tongeren, D.R., Hui, C.M., \& Hoyle, R.H. (in press). Self-control and forgiveness: A meta-analytic review. Social Psychological and Personality Science. doi: 10.1177/1948550613502991

Burnette, J.L., McCullough, M.E., Van Tongeren, D.R., \& Davis, D.E. (2012). Forgiveness results from integrating information about relationship value and exploitation risk. Personality and Social Psychology Bulletin, 38, 345-356. doi: 10.1177/0146167211424582

Buss, D.M., \& Shackelford, T.K. (1997). From vigilance to violence: Mate retention tactics in married couples. Journal of Personality and Social Psychology, 72, 346-361. doi: 10.1037/00223514.72.2.346

Buunk, B.P., \& Schaufeli, W.B. (1999). Reciprocity in interpersonal relationships: An evolutionary perspective on its importance for health and well-being. European Review of Social Psychology, 10, 259-291. doi: 10.1080/14792779943000080

Cann, A., \& Baucom, T.R. (2004). Former partners and new rivals as threats to a relationship: Infidelity type, gender, and commitment as factors related to distress and forgiveness. Personal Relationships, 11, 305-318. doi: 10.1111/j.1475-6811.2004.00084.x 
Clark, M.S., \& Grote, N.K. (1998). Why aren't indices of relationship costs always negatively related to indices of relationship quality? Personality \& Social Psychology Review, 2, 2-17. doi: 10.1207/s15327957pspr0201_1

Clark, M.S., Lemay, E.P., Graham, S.M., Pataki, S.P., \& Finkel, E.J. (2010). Ways of giving benefits in marriage: Norm use, relationship satisfaction, and attachment-related variability. Psychological Science, 21, 944-951. doi: 10.1177/0956797610373882

Clark, M.S., \& Mills, J. (1979). Interpersonal attraction in exchange and communal relationships. Journal of Personality and Social Psychology, 37, 12-24. doi: 10.1037/0022-3514.37.1.12

Clark, M.S., \& Mills, J. (1993). The difference between communal and exchange relationships: What it is and is not. Personality and Social Psychology Bulletin, 19, 684-691. doi: $10.1177 / 0146167293196003$

Clark, M.S., Oullette, R., Powell, M.C., \& Milberg, S. (1987). Recipient's mood, relationship type, and helping. Journal of Personality and Social Psychology, 53, 94-103. doi: 10.1037/00223514.53.1.94

Clark, M.S., \& Reis, H.T. (1988). Interpersonal processes in close relationships. Annual Review of Psychology, 39, 609-672. doi: 10.1146/annurev.ps.39.020188.003141

Custrona, C.E. (1996). Social support in couples: Marriage as a resource in times of stress. Thousand Oaks, CA: Sage.

DeWall, C.N., Baumeister, R.F., Gailliot, M.T., \& Maner, J.K. (2008). Depletion makes the heart grow less helpful: Helping as a function of self-regulatory energy and genetic relatedness. Personality and Social Psychology Bulletin, 34, 1653-1662. doi: 10.1177/0146167208323981 Downey, G., Freitas, A.L., Michaelis, B., \& Khouri, H. (1998). The self-fulfilling prophecy in close relationships: Rejection sensitivity and rejection by romantic partners. Journal of Personality and Social Psychology, 75, 545-560. doi: 10.1037/0022-3514.75.2.545 
Drigotas, S.M., Safstrom, C.A., \& Gentilia, T. (1999). An investment model prediction of dating infidelity. Journal of Personality and Social Psychology, 77, 509-524. doi: 10.1037/00223514.77.3.509

Dutton, D., van Ginkel, C., \& Landolt, M. (1996). Jealousy, intimate abusiveness, and intrusiveness. Journal of Family Violence, 11, 411-423. doi: 10.1007/bf02333425

Fennis, B.M. (2011). Can't get over me: Ego depletion attenuates prosocial effects of perspective taking. European Journal of Social Psychology, 41, 580-585. doi: 10.1002/ejsp.828

Finkel, E.J., \& Campbell, W.K. (2001). Self-control and accommodation in close relationships: An interdependence analysis. Journal of Personality and Social Psychology, 81, 263-277. doi: 10.1037/0022-3514.81.2.263

Finkel, E.J., DeWall, C.N., Slotter, E.B., Oaten, M., \& Foshee, V.A. (2009). Self-regulatory failure and intimate partner violence perpetration. Journal of Personality and Social Psychology, 97, 483499. doi: $10.1037 / \mathrm{a} 0015433$

Finkel, E.J., \& Eastwick, P.W. (in press). Interpersonal attraction: In search of a theoretical rosetta stone. In J. A. Simpson \& J. F. Dovidio (Eds.), Handbook of personality and social psychology: Interpersonal relations and group processes. Washington, DC: American Psychological Association.

Finkel, E.J., Hui, C.M., Carswell, K.D., \& Larson, G.M. (in press). The suffocation of marriage: Climbing mount maslow without enough oxygen. Psychological Inquiry.

Finkel, E.J., \& Rusbult, C.E. (2008). Prorelationship motivation: An interdependence theory analysis of situations with conflicting interests. In J. Y. Shah \& W. L. Gardner (Eds.), Handbook of motivation science (pp. 547-560). New York: Guilford. 
Finkel, E.J., Rusbult, C.E., Kumashiro, M., \& Hannon, P.A. (2002). Dealing with betrayal in close relationships: Does commitment promote forgiveness? Journal of Personality and Social Psychology, 82, 956-974. doi: 10.1037/0022-3514.82.6.956

Fitzsimons, G.M., \& Finkel, E.J. (2010). Interpersonal influences on self-regulation. Current Directions in Psychological Science, 19, 101-105. doi: 10.1177/0963721410364499

Fitzsimons, G.M., \& Fishbach, A. (2010). Shifting closeness: Interpersonal effects of personal goal progress. Journal of Personality and Social Psychology, 98, 535-549.

Fraley, R.C., \& Shaver, P.R. (2008). Attachment theory and its place in contemporary personality theory and research. In O. P. John, R. W. Robins \& L. A. Pervin (Eds.), Handbook of personality: Theory and research (3rd ed., pp. 518-541). New York: Guilford Press.

Gable, S.L., \& Reis, H.T. (2010). Good news! Capitalizing on positive events in an interpersonal context. In P. Z. Mark (Ed.), Advances in experimental social psychology (Vol. 42, pp. 195257). San Diego, CA: Academic Press.

Garcia, S.M., \& Harrison, B.J. (2007). Decision model of helping. In R. F. Baumeister \& K. D. Vohs (Eds.), Encyclopedia of social psychology (Vol. 1, pp. 228-229). Thousand Oaks, CA: Sage.

Gleason, M.E.J., Iida, M., Bolger, N., \& Shrout, P.E. (2003). Daily supportive equity in close relationships. Personality and Social Psychology Bulletin, 29, 1036-1045. doi: $10.1177 / 0146167203253473$

Hannon, P.A., Rusbult, C.E., Finkel, E.J., \& Kamashiro, M. (2010). In the wake of betrayal: Amends, forgiveness, and the resolution of betrayal. Personal Relationships, 17, 253-278. doi: $10.1111 / j .1475-6811.2010 .01275 . x$

Helgeson, V.S., \& Fritz, H.L. (1998). A theory of unmitigated communion. Personality and Social Psychology Review, 2, 173-183. doi: 10.1207/s15327957pspr0203_2 
Hofmann, W., Finkel, E.J., \& Fitzsimons, G.M. (2013). Relationships and self-regulation of daily goals. Unpublished manuscript.

Hofmann, W., \& Patel, P.V. (2013). Surveysignal: A convenient solution for experience-sampling research using participants' own smartphones. Unpublished manuscript.

Hui, C.M., Molden, D.C., \& Finkel, E.J. (2013). Loving freedom: Concerns with promotion or prevention and the role of autonomy in relationship well-being. Journal of Personality and Social Psychology, 105, 61-85. doi: 10.1037/a0032503

Impett, E.A., \& Gordon, A.M. (2008). For the good of others: Toward a positive psychology of sacrifice. In S. J. Lopez (Ed.), Positive psychology: Exploring the best in people (pp. 79-100). Westport, CT: Greenwood Publishing.

Impett, E.A., \& Gordon, A.M. (2010). Why do people sacrifice to approach rewards versus to avoid costs? Insights from attachment theory. Personal Relationships, 17, 299-315. doi: 10.1111/j.1475-6811.2010.01277.x

Johnson, D.J., \& Rusbult, C.E. (1989). Resisting temptation: Devaluation of alternative partners as a means of maintaining commitment in close relationships. Journal of Personality and Social Psychology, 57, 967-980. doi: 10.1037/0022-3514.57.6.967

Johnson, M.P. (1991). Commitment to personal relationships. In W. H. Jones \& D. Perlman (Eds.), Advances in personal relationships (Vol. 3, pp. 117-143). London, UK: Jessica Kingsley Publishers.

Johnson, M.P. (1999). Personal, moral, and structural commitment to relationships: Experiences of choice and constraint. In J. M. Adams \& W. H. Jones (Eds.), Handbook of interpersonal commitment and relationship stability (pp. 73-87). New York: Kluwer.

Johnson, M.P. (2008). A typology of domestic violence: Intimate terrorism, violence resistance, and situational couple violence. Lebanon, NH: Northeastern University Press. 
Karremans, J.C., Van Lange, P.A.M., \& Holland, R.W. (2005). Forgiveness and its associations with prosocial thinking, feeling, and doing beyond the relationship with the offender. Personality and Social Psychology Bulletin, 31, 1315-1326. doi: 10.1177/0146167205274892

Kelley, H.H., Holmes, J.G., Kerr, N.L., Reis, H.T., Rusbult, C.E., \& Van Lange, P.A.M. (2003). An atlas of interpersonal situations. Cambridge, England: Cambridge University Press.

Kelley, H.H., \& Thibaut, J.W. (1978). Interpersonal relations: A theory of interdependence. New York: Wiley.

Knee, C.R., Hadden, B.W., Porter, B., \& Rodriguez, L.M. (in press). Self-determination theory and romantic relationship processes. Personality and Social Psychology Review. doi: $10.1177 / 1088868313498000$

Knee, C.R., Lonsbary, C., Canevello, A., \& Patrick, H. (2005). Self-determination and conflict in romantic relationships. Journal of Personality and Social Psychology, 89, 997-1009. doi: $10.1037 / 0022-3514.89 .6 .997$

Knee, C.R., Patrick, H., Vietor, N.A., \& Neighbors, C. (2004). Implicit theories of relationships: Moderators of the link between conflict and commitment. Personality and Social Psychology Bulletin, 30, 617-628. doi: http://dx.doi.org/10.1177/0146167203262853

Kumashiro, M., Rusbult, C.E., \& Finkel, E.J. (2008). Navigating personal and relational concerns: The quest for equilibrium. Journal of Personality and Social Psychology, 95, 94-110. doi: 10.1037/0022-3514.95.1.94

La Guardia, J.G., \& Patrick, H. (2008). Self-determination theory as a fundamental theory of close relationships. Canadian Psychology/Psychologie canadienne, 49, 201-209. doi: $10.1037 / \mathrm{a} 0012760$

Latane, B., \& Darley, J.M. (1970). The unresponsive bystander: Why doesn't he help? . New York: Appleton-Century-Crofts. 
Le, B., \& Agnew, C.R. (2003). Commitment and its theorized determinants: A meta-analysis of the investment model. Personal Relationships, 10, 37-57. doi: 10.1111/1475-6811.00035

Le, B., Dove, N.L., Agnew, C.R., Korn, M.S., \& Mutso, A.A. (2010). Predicting nonmarital romantic relationship dissolution: A meta-analytic synthesis. Personal Relationships, 17, 377-390. doi: $10.1111 / \mathrm{j} .1475-6811.2010 .01285 . \mathrm{x}$

Le, B., Korn, M.S., Crockett, E.E., \& Loving, T.J. (2011). Missing you maintains us: Missing a romantic partner, commitment, relationship maintenance, and physical infidelity. Journal of Social and Personal Relationships, 28, 653-667. doi: 10.1177/0265407510384898

Lehmiller, J.J., \& Agnew, C.R. (2006). Marginalized relationships: The impact of social disapproval on romantic relationship commitment. Personality and Social Psychology Bulletin, 32, 40-51. doi: $10.1177 / 0146167205278710$

Liebrand, W.B.G., \& McClintock, C.G. (1988). The ring measure of social values: A computerized procedure for assessing individual differences in information processing and social value orientation. European Journal of Personality, 2, 217-230. doi: 10.1002/per.2410020304

Lin, S., Keysar, B., \& Epley, N. (2010). Reflexively mindblind: Using theory of mind to interpret behavior requires effortful attention. Journal of Experimental Social Psychology, 46, 551-556. doi: 10.1016/j.jesp.2009.12.019

Luchies, L.B., Finkel, E.J., McNulty, J.K., \& Kumashiro, M. (2010). The doormat effect: When forgiving erodes self-respect and self-concept clarity. Journal of Personality and Social Psychology, 98, 734-749. doi: 10.1037/a0017838

Lurie, S. (1987). A parametric model of utility for two-person distributions. Psychological Review, 94, 42-60. doi: 10.1037/0033-295X.94.1.42 
Lydon, J.E., Fitzsimons, G.M., \& Naidoo, L. (2003). Devaluation versus enhancement of attractive alternatives: A critical test using the calibration paradigm. Personality and Social Psychology Bulletin, 29, 349-359. doi: 10.1177/0146167202250202

McCullough, M.E., Rachal, K.C., Sandage, S.J., Worthington, E.L., Jr, Brown, S.W., \& Hight, T.L. (1998). Interpersonal forgiving in close relationships. Ii: Theoretical elaboration and measurement. Journal of Personality and Social Psychology, 75, 1586-1603. doi: $10.1037 / 0022-3514.75 .6 .1586$

Menzies-Toman, D.A., \& Lydon, J.E. (2005). Commitment-motivated benign appraisals of partner transgressions: Do they facilitate accommodation? Journal of Social and Personal Relationships, 22, 111-128. doi: 10.1177/0265407505049324

Molden, D.C., \& Finkel, E.J. (2010). Motivations for promotion and prevention and the role of trust and commitment in interpersonal forgiveness. Journal of Experimental Social Psychology, 46, 255-268. doi: 10.1016/j.jesp.2009.10.014

Murray, S.L., Aloni, M., Holmes, J.G., Derrick, J.L., Stinson, D.A., \& Leder, S. (2009). Fostering partner dependence as trust insurance: The implicit contingencies of the exchange script in close relationships. Journal of Personality and Social Psychology, 96, 324-348. doi: $10.1037 / \mathrm{a} 0012856$

Murray, S.L., \& Holmes, J.G. (2008). The commitment-insurance system: Self-esteem and the regulation of connection in close relationships. In M. P. Zanna (Ed.), Advances in experimental social psychology (Vol. 40, pp. 1-60). San Diego: Academic Press.

Murray, S.L., \& Holmes, J.G. (2009). The architecture of interdependent minds: A motivationmanagement theory of mutual responsiveness. Psychological Review, 116, 908-928. doi: $10.1037 / \mathrm{a} 0017015$

Murray, S.L., \& Holmes, J.G. (2011). Interdependent minds. New York: Guilford. 
Murray, S.L., Holmes, J.G., \& Collins, N.L. (2006). Optimizing assurance: The risk regulation system in relationships. Psychological Bulletin, 132, 641-666. doi: 10.1037/0033-2909.132.5.641

Nesse, R.M. (Ed.). (2001). Evolution and the capacity for commitment. New York: Russell Sage Foundation.

Overall, N.C., Fletcher, G.J.O., \& Simpson, J.A. (2006). Regulation processes in intimate relationships: The role of ideal standards. Journal of Personality and Social Psychology, 91, 662-685. doi: 10.1037/0022-3514.91.4.662

Overall, N.C., Fletcher, G.J.O., Simpson, J.A., \& Sibley, C.G. (2009). Regulating partners in intimate relationships: The costs and benefits of different communication strategies. Journal of Personality and Social Psychology, 96, 620-639. doi: 10.1037/a0012961

Pansera, C., \& La Guardia, J. (2012). The role of sincere amends and perceived partner responsiveness in forgiveness. Personal Relationships, 19, 696-711. doi: 10.1111/j.1475-6811.2011.01386.x

Paolacci, G., Chandler, J., \& Ipeirotis, P. (2010). Running experiments on amazon mechanical turk. Judgment and Decision Making, 5, 411-419.

Peugh, J.L., \& Enders, C.K. (2005). Using the spss mixed procedure to fit cross-sectional and longitudinal multilevel models. Educational and Psychological Measurement, 65, 717-741. doi: $10.1177 / 0013164405278558$

Powell, C., \& Van Vugt, M. (2003). Genuine giving or selfish sacrifice? The role of commitment and cost level upon willingness to sacrifice. European Journal of Social Psychology, 33, 403-412. doi: 10.1002/ejsp.154

Rai, T.S., \& Fiske, A.P. (2011). Moral psychology is relationship regulation: Moral motives for unity, hierarchy, equality, and proportionality. Psychological Review, 118, 57-75. doi: $10.1037 / \mathrm{a} 0021867$ 
Reis, H.T., Collins, W.A., \& Berscheid, E. (2000). The relationship context of human behavior and development. Psychological Bulletin, 126, 844-872. doi: 10.1037/0033-2909.126.6.844

Rempel, J.K., Holmes, J.G., \& Zanna, M.P. (1985). Trust in close relationships. Journal of Personality and Social Psychology, 49, 95-112. doi: 10.1037/0022-3514.49.1.95

Rhoades, G.K., Stanley, S.M., Kelmer, G., \& Markman, H.J. (2010). Physical aggression in unmarried relationships: The roles of commitment and constraints. Journal of Family Psychology, 24, 678-687. doi: 10.1037/a0021475

Rusbult, C.E. (1980). Commitment and satisfaction in romantic associations: A test of the investment model. Journal of Experimental Social Psychology, 16, 172-186. doi: 10.1016/00221031(80)90007-4

Rusbult, C.E. (1991). Commentary on johnson's 'commitment to personal relationships': What's interesting, and what's new? In W. H. Jones \& D. Perlman (Eds.), Advances in personal relationships (Vol. 3, pp. 151-170). London, UK: Jessica Kingsley Publishers.

Rusbult, C.E., \& Buunk, B.P. (1993). Commitment processes in close relationships: An interdependence analysis. Journal of Social and Personal Relationships, 10, 175-204. doi: $10.1177 / 026540759301000202$

Rusbult, C.E., Finkel, E.J., \& Kumashiro, M. (2009). The michelangelo phenomenon. Current Directions in Psychological Science, 18, 305-309. doi: 10.1111/j.1467-8721.2009.01657.x Rusbult, C.E., Martz, J.M., \& Agnew, C.R. (1998). The investment model scale: Measuring commitment level, satisfaction level, quality of alternatives, and investment size. Personal Relationships, 5, 357-387. doi: 10.1111/j.1475-6811.1998.tb00177.x

Rusbult, C.E., Olsen, N., Davis, J.L., \& Hannon, P.A. (2001). Commitment and relationship maintenance mechanisms. In J. Harvey \& W. Amy (Eds.), Close romantic relationships: 
Maintenance and enhancement (pp. 87-113). Mahwah, New Jersey: Lawrence Erlbaum Associates.

Rusbult, C.E., Olsen, N., Davis, J.L., \& Hannon, P.A. (2004). Commitment and relationship maintenance mechanisms. In H. T. Reis \& C. Rusbult (Eds.), Close relationships: Key readings (pp. 287-303). New York: Psychology Press.

Rusbult, C.E., Verette, J., Whitney, G.A., Slovik, L.F., \& Lipkus, I. (1991). Accommodation processes in close relationships: Theory and preliminary empirical evidence. Journal of Personality and Social Psychology, 60, 53-78. doi: 10.1037/0022-3514.60.1.53

Sackett, L.A., \& Saunders, D.G. (1999). The impact of different forms of psychological abuse on battered women. Violence and Victims, 14, 105-117.

Slotter, E.B., \& Finkel, E.J. (2009). The strange case of sustained dedication to an unfulfilling relationship: Predicting commitment and breakup from attachment anxiety and need fulfillment within relationships. Personality and Social Psychology Bulletin, 35, 85-100. doi: $10.1177 / 0146167208325244$

Slotter, E.B., Finkel, E.J., DeWall, C.N., Lambert, N.M., Pond, R.S., Bodenhausen, G.V., \& Fincham, F.D. (2012). Putting the brakes on aggression toward a romantic partner: The inhibitory influence of relationship commitment. Journal of Personality and Social Psychology, 102, 291305. doi: $10.1037 / \mathrm{a} 0024915$

Slotter, E.B., \& Gardner, W.L. (2011). How needing you changes me: The influence of attachment anxiety on self-concept malleability in romantic relationships. Self and Identity, 000-000. doi: $10.1080 / 15298868.2011 .591538$

Tran, S., \& Simpson, J.A. (2009). Prorelationship maintenance behaviors: The joint roles of attachment and commitment. Journal of Personality and Social Psychology, 97, 685-698. doi: $10.1037 / \mathrm{a} 0016418$ 
Uehara, E.S. (1995). Reciprocity reconsidered: Gouldner's `moral norm of reciprocity' and social support. Journal of Social and Personal Relationships, 12, 483-502. doi: $10.1177 / 0265407595124001$

Van Lange, P.A.M. (2000). Beyond self-interest: A set of propositions relevant to interpersonal orientations. European Review of Social Psychology, 11, 297-331. doi: $10.1080 / 14792772043000068$

Van Lange, P.A.M., Agnew, C.R., Harinck, F., \& Steemers, G.E.M. (1997). From game theory to real life: How social value orientation affects willingness to sacrifice in ongoing close relationships. Journal of Personality and Social Psychology, 73, 1330-1344. doi: 10.1037/00223514.73.6.1330

Van Lange, P.A.M., \& Joireman, J.A. (2008). How we can promote behavior that serves all of us in the future. Social Issues and Policy Review, 2, 127-157. doi: 10.1111/j.1751-2409.2008.00013.x

Van Lange, P.A.M., Klapwijk, A., \& Van Munster, L.M. (2011). How the shadow of the future might promote cooperation. Group Processes \& Intergroup Relations, 14, 857-870. doi: $10.1177 / 1368430211402102$

Van Lange, P.A.M., Otten, W., De Bruin, E.M.N., \& Joireman, J.A. (1997). Development of prosocial, individualistic, and competitive orientations: Theory and preliminary evidence. Journal of Personality and Social Psychology, 73, 733-746. doi: 10.1037/0022-3514.73.4.733

Van Lange, P.A.M., Ouwerkerk, J.W., \& Tazelaar, M.J.A. (2002). How to overcome the detrimental effects of noise in social interaction: The benefits of generosity. Journal of Personality and Social Psychology, 82, 768-780. doi: 10.1037/0022-3514.82.5.768

Van Lange, P.A.M., Rusbult, C.E., Drigotas, S.M., Arriaga, X.B., Witcher, B.S., \& Cox, C.L. (1997). Willingness to sacrifice in close relationships. Journal of Personality and Social Psychology, 72, 1373-1395. doi: 10.1037/0022-3514.72.6.1373 
Wieselquist, J., Rusbult, C.E., Foster, C.A., \& Agnew, C.R. (1999). Commitment, prorelationship behavior, and trust in close relationships. Journal of Personality and Social Psychology, 77, 942-966. doi: 10.1037/0022-3514.77.5.942

Wu, J., \& Axelrod, R. (1995). How to cope with noise in the iterated prisoner's dilemma. Journal of Conflict Resolution, 39, 183-189. 


\section{Author Note}

Chin Ming Hui, Booth School of Business, University of Chicago; Eli J. Finkel, Department of Psychology, Northwestern University; Gráinne M. Fitzsimons, Department of Psychology and Neuroscience, Duke University; Madoka Kumashiro, Department of Psychology, Goldsmiths, University of London, London, England; Wilhelm Hofmann, Department of Psychology, University of Cologne, Germany.

This research was supported by National Science Foundation Grants BCS-719780 and BCS0951571 (to Finkel) and BCS-0132398 (to Caryl E. Rusbult) and by funding from the Fetzer Institute. All opinions and conclusions are those of the authors and do not necessarily reflect the opinions of the funding agencies.

Address correspondence to Chin Ming Hui, Booth School of Business, University of Chicago, Chicago, IL 60637, Email: Ming.Hui@ chicagobooth.edu 
Table 1

Multilevel Hierarchical Regression Analyses on Priority in Goal Pursuit in Study 1a

\begin{tabular}{lcc}
\hline \multicolumn{1}{c}{ Predictor } & $\beta$ & $t$ \\
\hline Relationship commitment & .01 & .12 \\
Relationship satisfaction & .06 & 1.05 \\
Self-interests & .25 & $9.19^{* * *}$ \\
Partner's interests & .12 & $4.31^{* * *}$ \\
Relationship's interests & .21 & $6.93^{* * *}$ \\
Commitment $\times$ Self & -.00 & -.11 \\
Commitment $\times$ Partner & -.06 & -1.42 \\
Commitment $\times$ Relationship & .10 & $1.95^{*}$ \\
Satisfaction $\times$ Self & -.04 & -1.03 \\
Satisfaction $\times$ Partner & .02 & .42 \\
Satisfaction $\times$ Relationship & -.04 & .80 \\
\hline
\end{tabular}

$\overline{\text { Note. }{ }^{*} p} \leq \overline{.05 . * * * p} \leq \overline{.001 .}$ 
Table 2

Multilevel Hierarchical Regression Analyses on Effort in Goal Pursuit in Study $1 b$

\begin{tabular}{lcc}
\hline \multicolumn{1}{c}{ Predictor } & $\beta$ & $t$ \\
\hline Relationship commitment & .07 & 1.77 \\
Relationship satisfaction & .01 & .36 \\
Self-interests & .19 & $9.35^{* * *}$ \\
Partner's interests & .01 & .64 \\
Relationship's interests & .11 & $3.86^{* * *}$ \\
Time & -.04 & $-3.39^{*}$ \\
Commitment $\times$ Self & .05 & $2.31^{*}$ \\
Commitment $\times$ Partner & .03 & -1.14 \\
Commitment $\times$ Relationship & .07 & $2.11^{*}$ \\
Satisfaction $\times$ Self & .02 & 1.14 \\
Satisfaction $\times$ Partner & .01 & .44 \\
Satisfaction $\times$ Relationship & .01 & .29 \\
\hline Note * $x \leq .05 * * * p .001$. & & \\
\hline
\end{tabular}

$\overline{\text { Note. }{ }^{*} p} \leq \overline{.05 . * * * p} \leq \overline{.001 .}$ 
Table 3

Hierarchical Regression Analyses on Support for Partner's Goal Pursuit in Study $2 a$

\begin{tabular}{lcc}
\hline \multicolumn{1}{c}{ Predictor } & $\beta$ & $t$ \\
\hline Relationship commitment & .10 & -.90 \\
Relationship satisfaction & .25 & $2.41^{*}$ \\
Threat $(1=$ High, $-1=$ Low $)$ & -.37 & $-5.12^{* * *}$ \\
Commitment $\times$ Threat & -.23 & $-2.17^{*}$ \\
Satisfaction $\times$ Threat & .14 & 1.30
\end{tabular}

$\overline{\text { Note. Degrees of freedom for } t \text {-statistics: Step } 1 \text { (main effects) }}=153$, Step 2 (interactions) $=151{ }^{*} p \leq$ $.05 . * * * p \leq .001$. 
Table 4

Hierarchical Regression Analyses on Support for Partner's Goal Pursuit in Study $2 b$

\begin{tabular}{lcc}
\hline \multicolumn{1}{c}{ Predictor } & $\beta$ & $t$ \\
\hline Relationship commitment & -.00 & -.02 \\
Threat & -.30 & $-2.14^{*}$ \\
Commitment $\times$ Threat & -.37 & $-2.76^{* *}$ \\
\hline
\end{tabular}

Note. Degrees of freedom for $t$-statistics: Step 1 (main effects) $=48$, Step 2 (interactions) $=47$.

$* p \leq .05 . * * * p \leq .01$. 
Table 5

Multilevel Hierarchical Regression Analyses on Support for Partner's Goal Pursuit in Study 3

\begin{tabular}{|c|c|c|}
\hline Predictor & $\beta$ & $t$ \\
\hline Daily relationship commitment & .03 & 1.32 \\
\hline Daily relationship satisfaction & .13 & $5.28 * * *$ \\
\hline Daily relationship threat & -.15 & $-4.11 * * *$ \\
\hline Daily personal threat & -.03 & -1.03 \\
\hline Time & -.03 & -1.19 \\
\hline Commitment $\times$ Relationship threat & -.05 & $-1.97 *$ \\
\hline Commitment $\times$ Personal threat & .06 & $2.14 *$ \\
\hline Satisfaction $\times$ Relationship threat & .05 & 1.52 \\
\hline Satisfaction $\times$ Personal threat & .01 & .20 \\
\hline
\end{tabular}


Table 6

Hierarchical Regression Analyses on Support for Partner in Study 4

\begin{tabular}{lcc}
\hline \multicolumn{1}{c}{ Predictor } & $\beta$ & $t$ \\
\hline Relationship commitment & .13 & 1.05 \\
Relationship satisfaction & .08 & .64 \\
Threat $(1=$ High, $-1=$ Low $)$ & -.49 & $-5.07 * * *$ \\
Commitment $\times$ Threat & -.27 & $-2.12^{*}$ \\
Satisfaction $\times$ Threat & .12 & 1.01
\end{tabular}

$\overline{\text { Note. } \text { Degrees of freedom for } t \text {-statistics: Step } 1 \text { (main effects) }}=77$, Step 2 (interactions) $=75 .{ }^{*} p \leq$ $.05 . * * * p \leq .001$. 


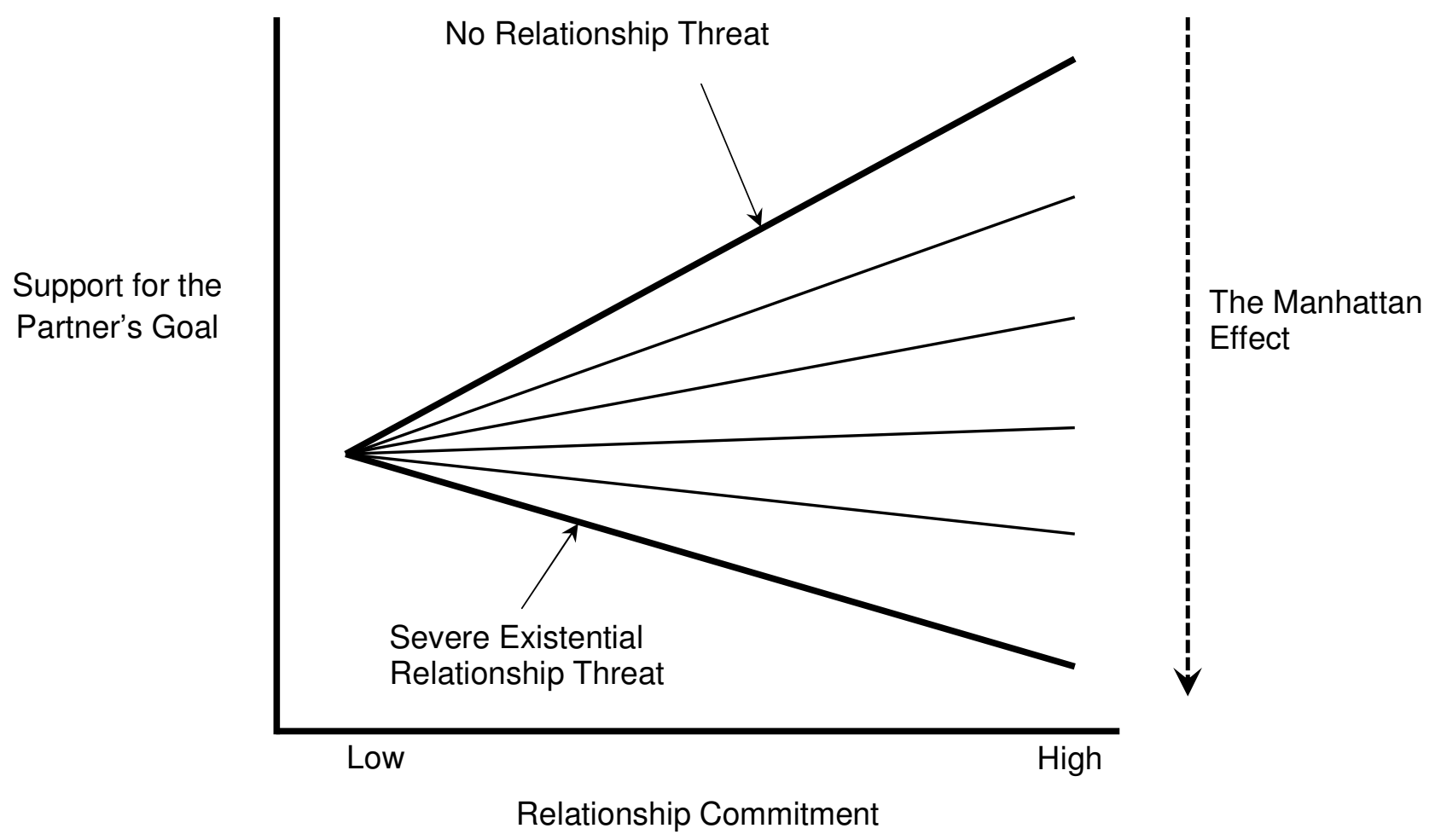

Figure 1. The Manhattan effects as a function of relationship commitment and relationship threat posed by the partner's goal. 
The Manhattan Effect 80

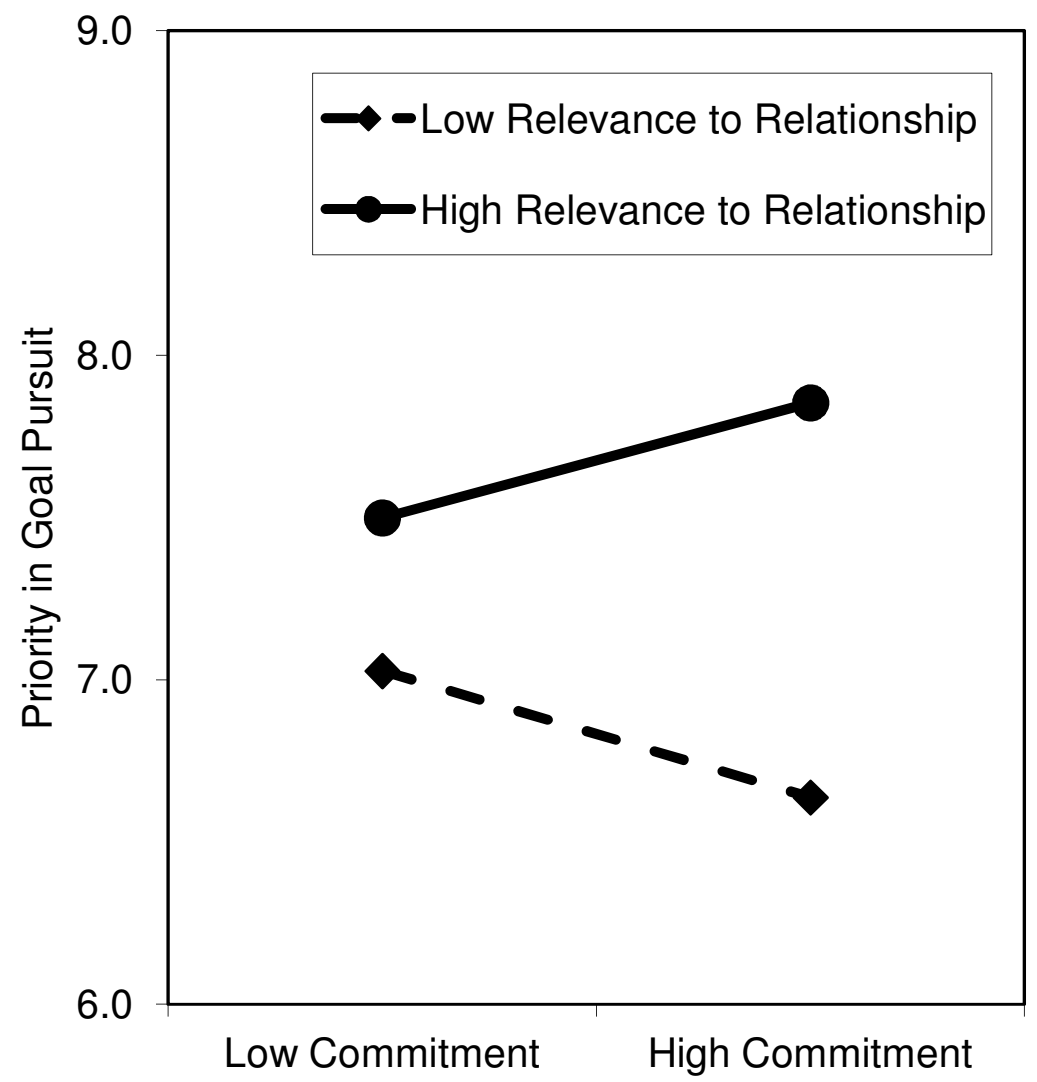

Figure 2. Priority in goal pursuit as a function of relationship commitment and the goal relevance to relationship's interests (Study 1a). 
The Manhattan Effect 81

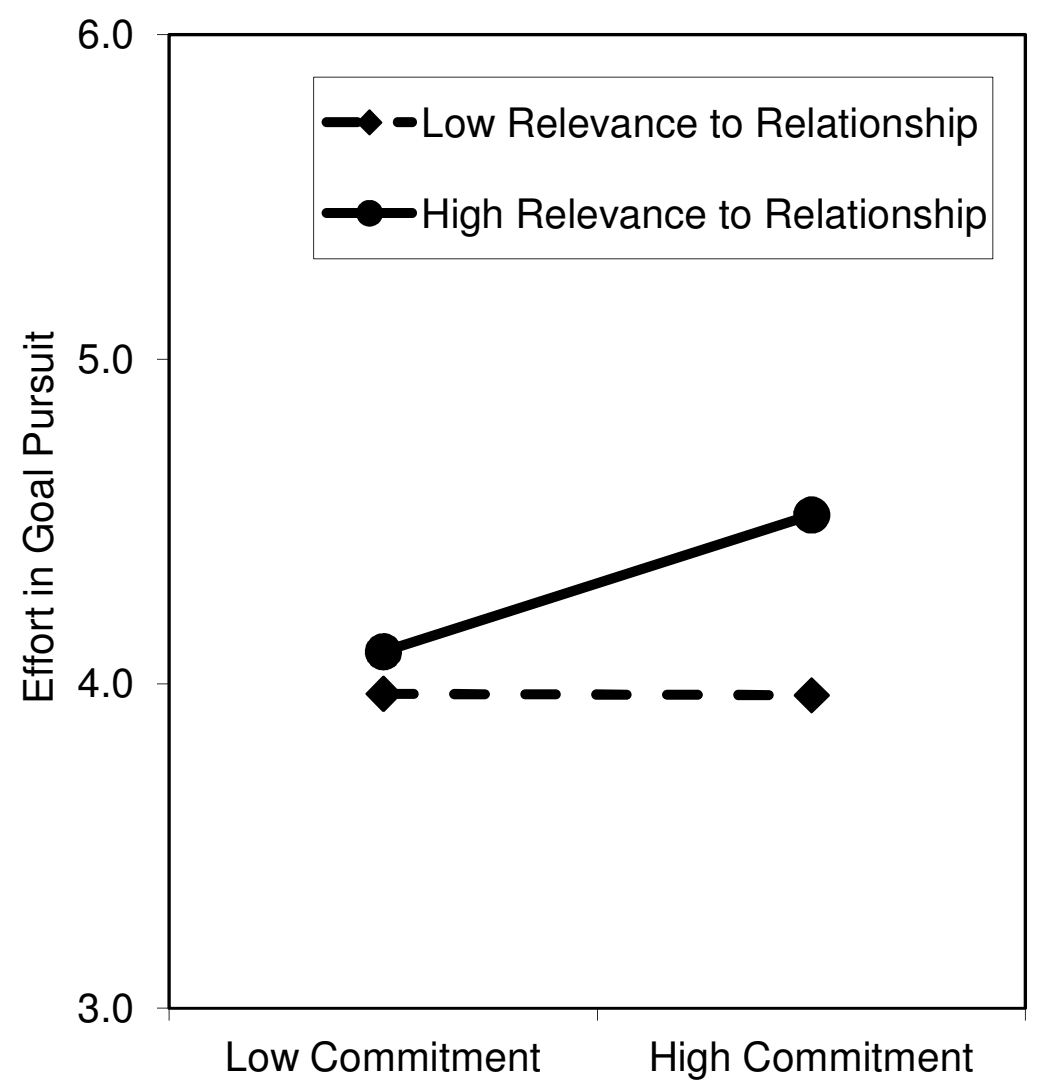

Figure 3. Effort in goal pursuit as a function of relationship commitment and the goal relevance to relationship's interests (Study $1 b$ ). 
The Manhattan Effect 82

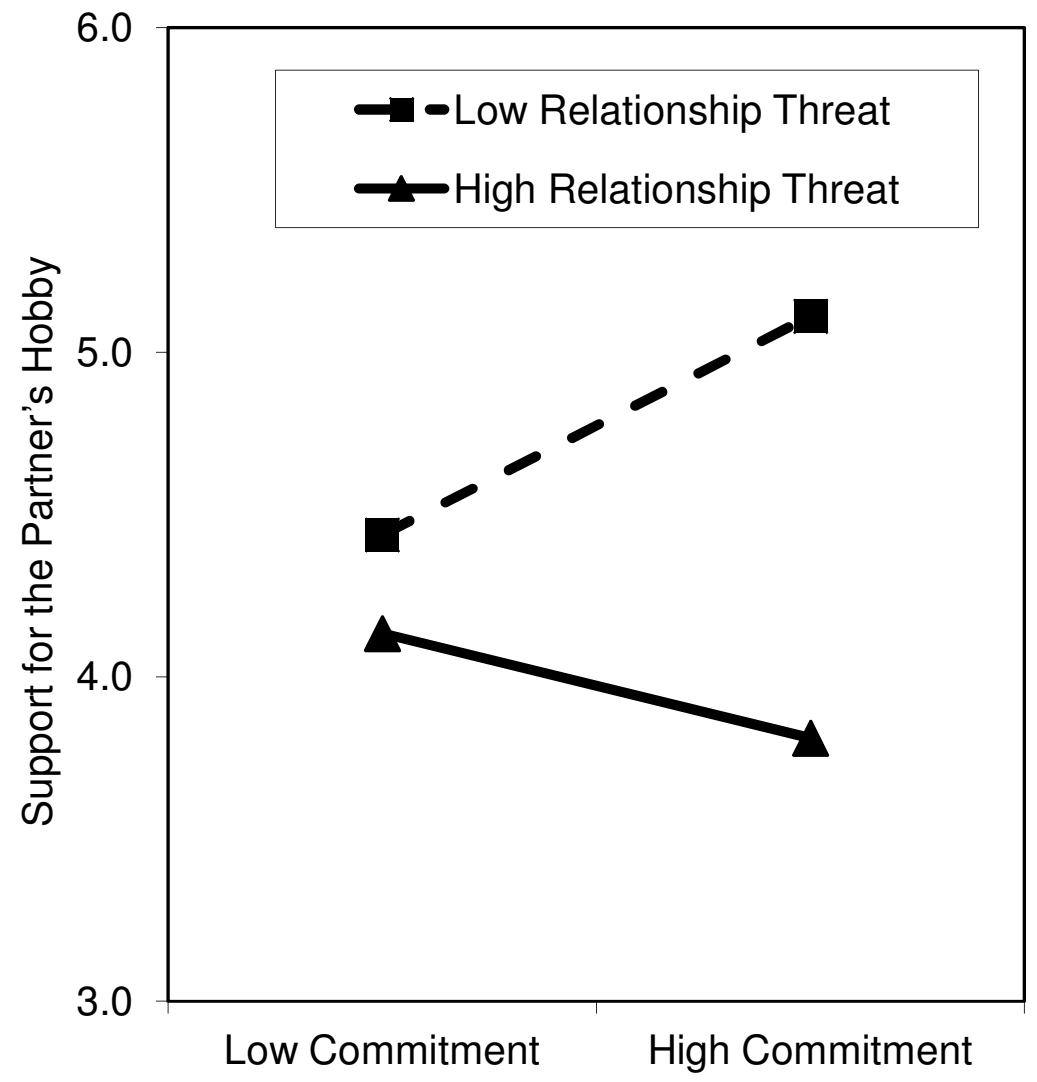

Figure 4. Support for the partner's pursuit of a personal hobby as a function of relationship commitment and relationship threat (Study 2a). 
The Manhattan Effect 83

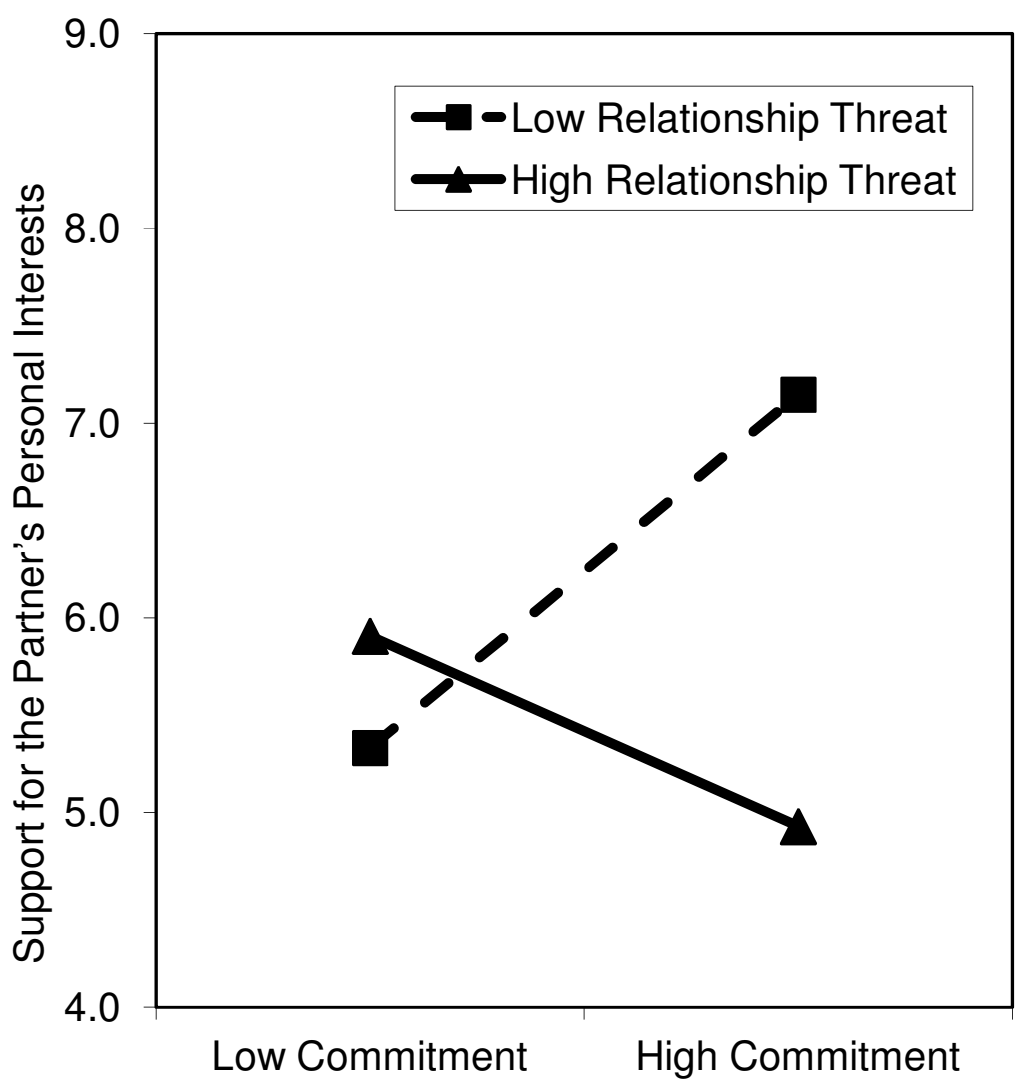

Figure 5. Support for the partner's personal interests as a function of relationship commitment and relationship threat (Study $2 b$ ). 
The Manhattan Effect 84

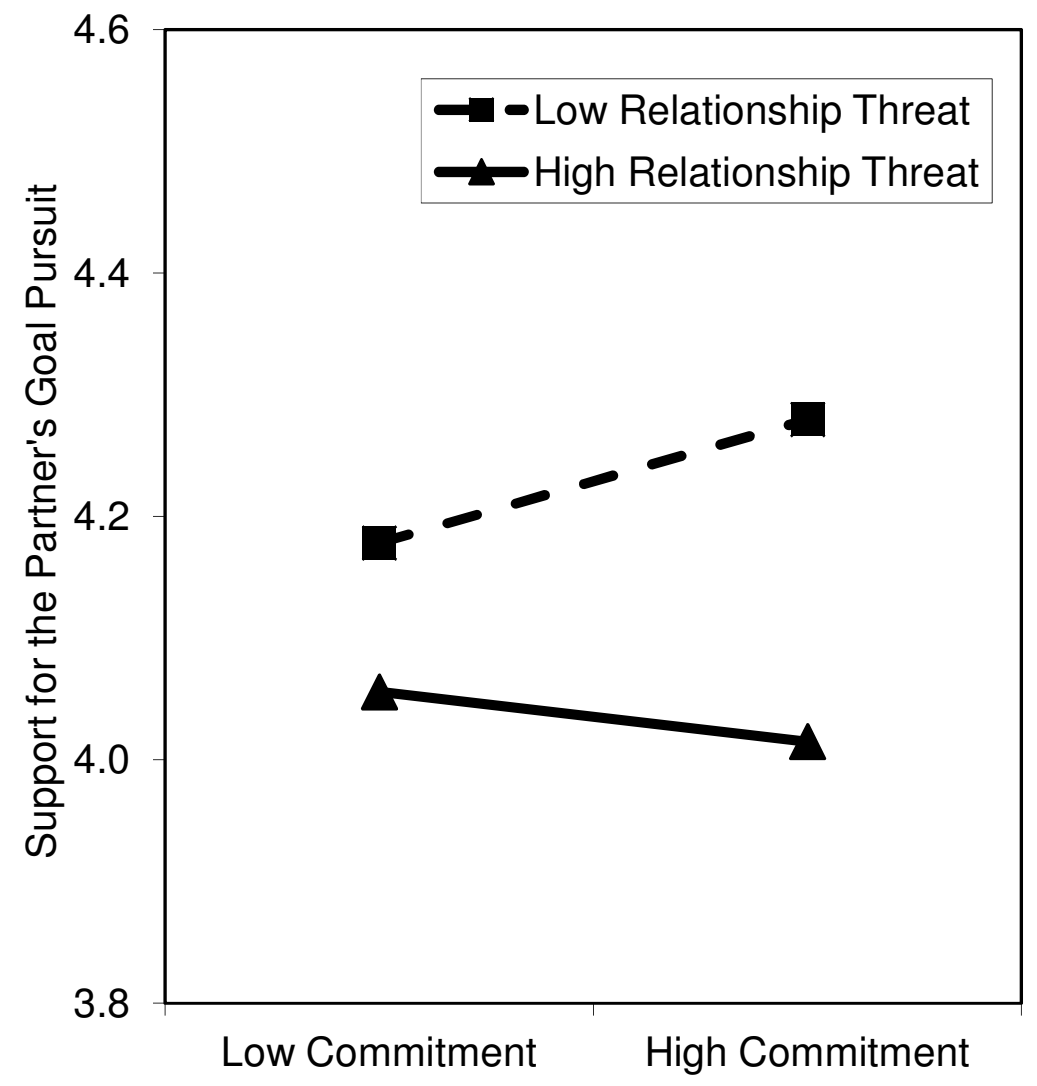

Figure 6. Support for the partner's goal pursuit as a function of relationship commitment and relationship threat (Study 3). 
The Manhattan Effect 85

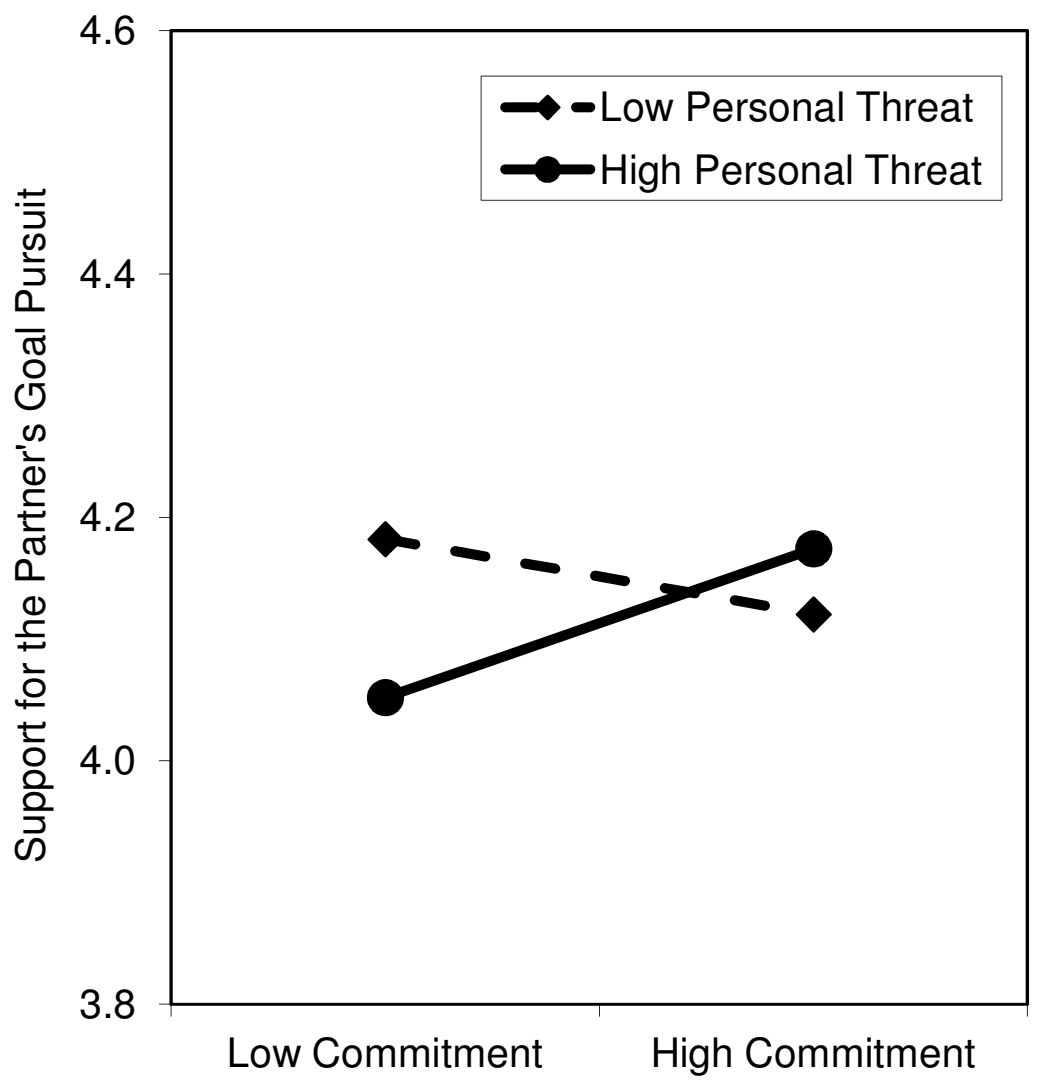

Figure 7. Support for the partner's goal pursuit as a function of relationship commitment and personal threat (Study 3). 
The Manhattan Effect 86

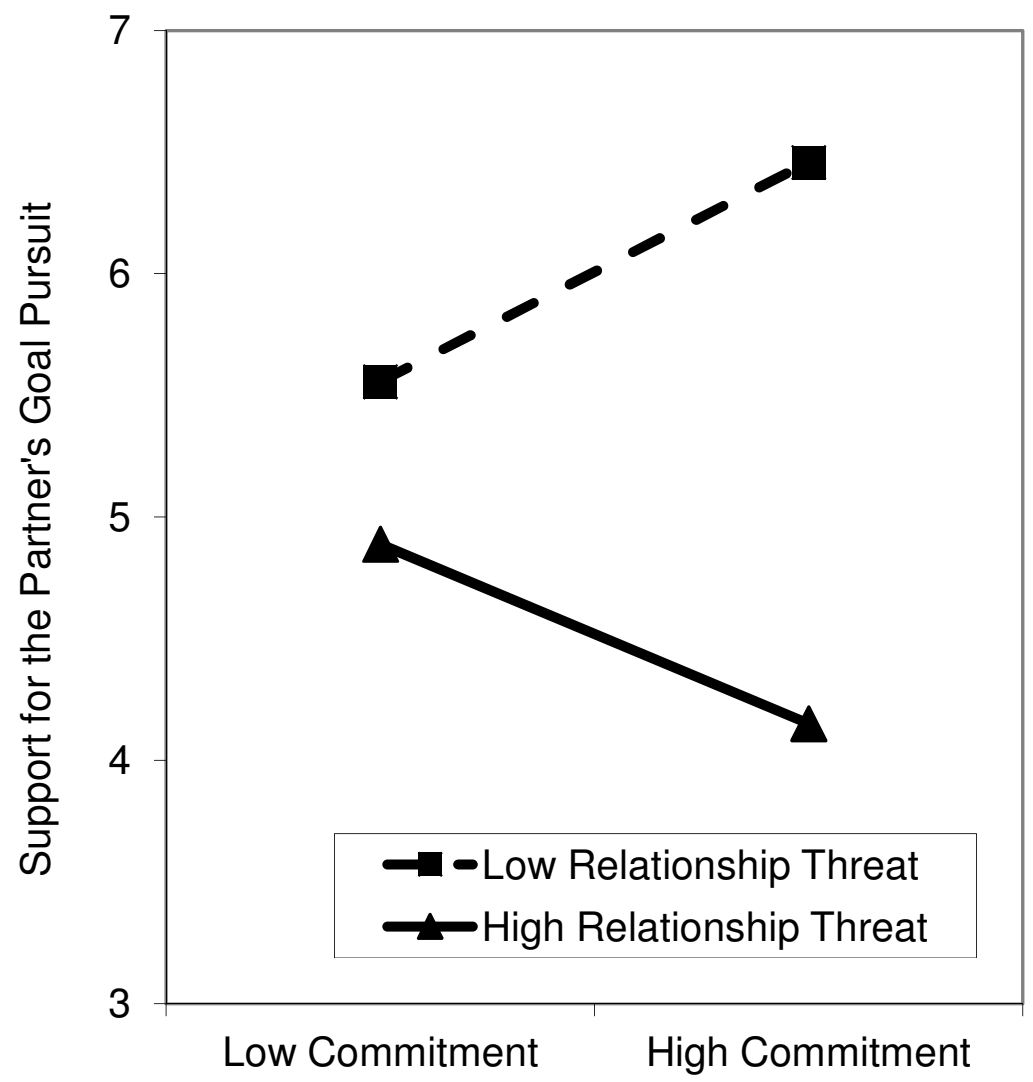

Figure 8. Support for the partner's goal pursuit as a function of relationship commitment and personal threat (Study 4). 
The Manhattan Effect 87

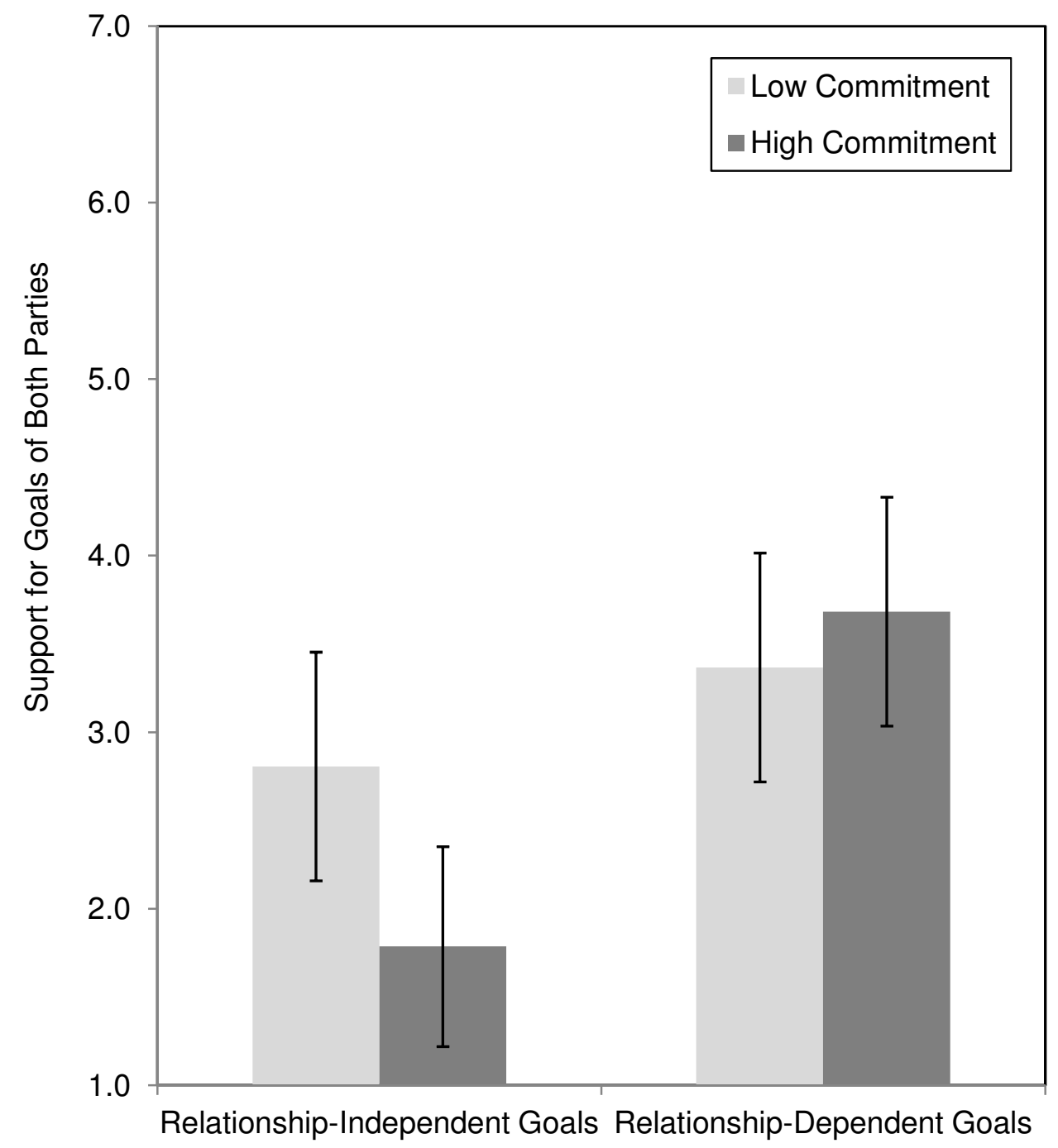

Figure 9. Support for goals of both parties under existential relationship threat as a function of relationship commitment and types of goals involved. Error bars represent $95 \%$ confident interval (Study 6). 